\title{
REGULACIÓN CONSTITUCIONAL Y LEGAL DE LA PROPIEDAD SOBRE EL DERECHO DE APROVECHAMIENTO DE AGUAS: TENSIONES ACTUALES Y PROPUESTAS PARA SU MODIFICACIÓN
}

\section{CONSTITUTIONAL AND LEGAL REGULATION OF WATER RIGHTS: CURRENT STRAINTS AND PROPOSALS FOR THEIR AMENDMENT}

Tatiana Celume Byrne*

\section{RESUMEN}

El presente artículo ilustra los aspectos patrimoniales a los que se encuentra sometido el derecho de aprovechamiento de aguas en la lógica constitucional y los efectos que, de dicha propietarización, se irradian en la legislación de aguas. De este modo, el objetivo de este trabajo es demostrar cuáles son los alcances del dominio sobre el derecho de aprovechamiento y hasta qué punto dicha institución se puede encuadrar dentro de la lógica patrimonial privada del derecho común. Asimismo, analizaremos cómo las modificaciones propuestas al contenido del derecho de aprovechamiento pueden tensar -hasta fracturar- la vinculación de dicha titularidad con las categorías de la propiedad civilmente regulada.

PALABRAS ClaVe: Derecho de aprovechamiento de aguas; propiedad, destinación de uso; priorización consumo humano y doméstico; derecho humano al agua.

* Doctora en Derecho por la Universidad de Salamanca, España. Docente investigadora de la Universidad San Sebastián, sede Bellavista, Santiago de Chile. Este artículo se inserta dentro del marco del proyecto Fondecyt de Iniciación n. ${ }^{\circ} 11180644$, del cual la autora es investigadora principal. Correo electrónico: tatiana.celume@uss.cl

Recepción: 2021-05-28; aceptación: 2021-07-19. 


\begin{abstract}
This paper illustrates the patrimonial aspects to which the water rights are subject in the constitutional logic and the effects that, of said ownership, radiate the water legislation. The purpose of this paper is to demonstrate what is the scope of the domain over the water rights and to what extent the said institution can be framed within the private patrimonial logic of Civil law. Likewise, it will be analyzed how the proposed amendments to the content of the water rights can strain -until fracture- the link of said ownership with the categories of civil property.
\end{abstract}

KEYWORDs: Water rights; property; destination of use; prioritization of human and domestic consumption; human right to water.

\title{
INTRODUCCIÓN
}

La CPR de 1980 no ha reservado una regulación especial de las aguas, sea estatizándolas o reconociéndolas como bienes públicos en su art. 19 núm. 23. En su summa divisio rerum exceptúa de apropiación a los res communes omnium y a aquellos bienes que deban pertenecer a la nación toda y la ley lo declare así, relegando a las aguas en esta última categoría (la de los bienes nacionales de uso público), de conformidad con lo ya dispuesto en la legislación civil ${ }^{1}$.

Sin embargo, y en oposición a la insusceptibilidad de apropiación privada de las aguas en su fuente, la libertad para adquirir toda clase bienes tiene aplicación en las titularidades para aprovecharlas, es decir, sobre el derecho de aprovechamiento. En este sentido, el TC ha sostenido:

"Esta libertad [la de adquirir toda clase de bienes] tiene como sustento el aseguramiento de la posibilidad jurídica de adquirir el dominio o de ser titular de toda forma de propiedad. Así, no puede

${ }^{1}$ Los primeros dos incisos del art. 589 del Código Civil disponen: "Se llaman bienes nacionales aquellos cuyo dominio pertenece a la nación toda. // Si además su uso pertenece a todos los habitantes de la nación, como el de calles, plazas, puentes y caminos, el mar adyacente y sus playas, se llaman bienes nacionales de uso o bienes públicos". A su vez, el art. 595 del mismo texto legal dispone: "Todas las aguas son bienes nacionales de uso público". Cuando esta última disposición se refiere a "todas las aguas", se excluye a las aguas marinas. Lo anterior, porque esta norma fue fruto de la reforma introducida por la Ley . $^{\circ} 16640$, de Reforma Agraria y su objetivo fue poner fin a la antigua división que existía entre las aguas públicas y las privadas (vertientes y lagos menores contenidos dentro de una misma heredad). 
resultar inconstitucional una norma que regula la forma de asignar derechos de aprovechamiento de aguas, pues en ella no se aprecia interés alguno del Estado por apropiarse éstos" ${ }^{2}$.

De este modo, y a partir de la distinción regulatoria de las aguas en cuanto fuente natural de abastecimiento (bien nacional de uso público) y DAA (facultad para aprovechar las aguas), se origina la posibilidad de apropiarse de este último y de someterlo al estatuto constitucional de la propiedad.

La preocupación fundamental del constituyente estuvo en la propietarización del $\mathrm{DAA}^{3}$, para lo cual lo incluyó expresamente dentro del estatuto de protección al dominio ${ }^{4}$. Ello se tradujo en la creación de una reserva legal para adquirir, limitar o restringir los derechos en virtud de la función social y para resguardarlo con el ejercicio de la acción constitucional de protección. Pero la $C P R$ no estableció un marco mínimo de contenidos que el legislador hubiese debido de tener en cuenta al momento de regular los caracteres del DAA. Al contrario, su silencio le imprimió al DAA de las máximas prerrogativas en el uso, goce y disposición de las aguas. Por ello, es aquel quien ha definido los contornos más precisos de los DAA, dibujando las implicancias del carácter público de las aguas. Así, el DAA diseñado por el $C A$ de 1981 consiste en un derecho indefinido (perpetuo), de obtención y mantención gratuita (exento del pago de una tarifa para amparar su tenencia), libremente transferible, no condicionado a un uso específico y no sujeto a mayores limitaciones de carácter ambiental (con las excepciones más recientes del caudal ecológico -que, como veremos, es de aplicación limitada- y de la posibilidad de que la Administración sujete su otorgamiento a ciertas modalidades con el objetivo de conservar el ambiente o proteger derechos de terceros $)^{5}$. Como concluyen Fernando Atria y Constanza Salgado "el régimen chileno de las aguas está claramente entre los más liberalizados del mundo"6.

${ }^{2}$ H. L. y otros (2006), considerando $28 .^{\circ}$.

${ }^{3}$ Para Celume (2013), pp. 86-87: "De la revisión de las sesiones pertinentes de la Comisión Ortúzar se desprende que el debate se centró fundamentalmente en la manera en que debía protegerse la titularidad del derecho particular que recayera sobre las aguas y no en la calificación jurídica de las mismas previo a su extracción”.

${ }^{4}$ Con anterioridad, el Código de Aguas de 1967 se inspiraba en un modelo de gestión asentado en la intervención estatal y en el establecimiento de tasas de uso racional y beneficioso que "iban a ser determinadas por científicos y técnicos del gobierno [...]". BAUER (2002), p. 68. Podemos entender que la utilización y la calidad de las aguas estaba ligada a un concepto de uso común en el que el aprovechamiento por parte de un usuario no podía ir en perjuicio de la fuente ni de los demás usuarios.

${ }^{5}$ Arts. 129 bis 1 y 149 núm. 7 del $C A$, respectivamente.

${ }^{6}$ Atria y Salgado (2015), p. 69. 
Consecuencia de ello es que, a partir de 1981, el $C A$ se ha asentado sobre el principio del otorgamiento y la reasignación de los derechos de aprovechamiento de aguas a sus usos de mayor valor, estableciéndose "un modelo de mercado como forma de reasignación al acceso a las aguas para fines extractivos"?.

A partir de estas premisas, sostenemos como hipótesis que la reconducción de los DAA a las categorías y lógicas del derecho civil provoca ciertas fricciones que petrifican el interés público que justifica la publificación de las aguas en la reasignación a sus usos de mayor valor, dificultando la incorporación de variables para priorizar el uso para el consumo humano, proteger la polifuncionalidad de las aguas y el resguardo de su función ambiental y su pleno reconocimiento como derecho humano. Para estos efectos, el presente artículo lo estructuramos de la siguiente manera: comenzaremos explicando cómo se configura y en qué se traduce la inclusión de los DAA en el estatuto de la propiedad regulada en la $C P R$. En este sentido, revisaremos cómo aquel sistema influyó en la creación de los mecanismos para limitar el otorgamiento de nuevos DAA y restringir su ejercicio. Luego, revisaremos el alcance de la propietarización de los derechos en la legislación de aguas y las fricciones que a la categoría civilista del dominio se producen a partir de ella. Y, por último, elaboraremos ciertas propuestas constitucionales que podrían orientar al legislador en la configuración de los DAA para modificar los supuestos sobre los que descansa la actual publificación del recurso. En este último apartado, demostraremos hasta qué punto, con dichas propuestas, es útil reconocer el derecho de propiedad sobre el derecho de aprovechamiento garantizado por la $C P R$ y en qué medida conviene que un marco regulatorio basal se encuentre dispuesto en la Carta Fundamental.

\section{LA PROTECCIÓN CONSTITUCIONAL DEL DAA}

Según dispone el artículo 19, núm. 24, inciso final de la CPR: "Los derechos de los particulares, constituidos o reconocidos en conformidad a la ley, otorgarán a sus titulares la propiedad sobre ellos". Como puntualiza Alejandro Vergara: "Hoy la propiedad, en su acepción constitucional (art. 19 n. ${ }^{\circ} 24$ ), es más bien una garantía: la titularidad protegida. Es una suprainstitución" ". Ello implica asumir que la subsunción del DAA en la $C P R$ se traduce en dotar a esta titularidad de todas las características y del contenido que asegura el estatuto de la propiedad regulada en el art. 19

\footnotetext{
${ }^{7}$ Celume (2013), p. 228.

${ }^{8}$ Vergara (2011), p. XV.
} 
núm. 24 incisos primero al quinto ${ }^{9}$. Además, supone que, al estar incorporados en el régimen de la propiedad constitucional, los DAA gozan de las acciones que respecto a la propiedad la $C P R$ ha dispuesto. En este sentido, sus titulares no pueden ser amenazados ni perturbados o privados del libre ejercicio de su derecho, ya que disponen de la acción constitucional de protección, contemplada en el art. de la $C P R$.

Fluye del texto constitucional transcrito supra que la subsunción al estatuto constitucional de la propiedad se refiere al DAA y no a las aguas propiamente tales, las que siguen siendo calificadas como bienes nacionales de uso público y, por tanto, ajenos a un estatuto dominical. En este sentido el TC ha resuelto:

"La Constitución asegura el dominio no sobre las aguas mismas, que constituyen bienes nacionales de uso público, sino sobre el derecho de aprovechamiento de ellas constituido en conformidad a la ley" ${ }^{10}$.

Como indica Alejandro Vergara:

"A través de esta referencia explícita se entrega a los particulares una estabilidad regulatoria, principalmente en cuanto a la garantía de la propiedad; esto es, una intangibilidad de los derechos de los particulares sobre sus derechos de aprovechamiento de aguas"11.

La connotación de la propietarización del DAA y su consecuente reserva legal implica diversas consecuencias para la obtención del derecho, su mantención y su protección, las que analizamos a continuación.

\section{Solo la ley puede determinar el modo de adquirir los derechos de aprovechamiento de aguas}

Como señala María Pía Silva:

"Al reservar a la ley la regulación de la propiedad, se impide que lo pueda hacer un decreto con fuerza de ley, reglas emanadas de

\footnotetext{
${ }^{9}$ Para algunos autores, como GuZmán y RAVERA (1996), p. 258: "En este caso el constituyente habló, correctamente, de propiedad sobre los derechos concernientes a las aguas. Pero, al igual que en el caso de los derechos mineros, el precepto es totalmente superfluo. La propiedad de los derechos de aguas, en efecto, asimismo ya queda garantizada por el inc. 1, pues de nuevo estamos en presencia de bienes incorporales".

${ }^{10}$ Grupo Cámara de Diputados de Chile (1997), considerando 7. ${ }^{\circ}$.

${ }^{11}$ Vergara (2017), p. 20.
} 
la potestad reglamentaria del Ejecutivo o cualquiera otra norma de inferior jerarquía a la de la ley común"12.

Por su parte, el TC ha resuelto:

"La normativa constitucional contiene un mandato habilitante al legislador para establecer bajo qué condiciones y requisitos se adquieren derechos sobre las aguas [...]"13.

Esta misma magistratura ha dispuesto qué tipo de ley es la encargada de determinar los modos de adquirir el DAA, al señalar:

"Considerando el artículo 19, No 24, inciso final, se concluye que el constituyente con meridiana claridad ha entregado a la 'ley', sin calificativos, la regulación o constitución del derecho sobre las aguas y, en consecuencia, el intérprete debe entender que tal ley es la ley común u ordinaria, tanto porque cuando la Constitución se refiere a la 'ley' sin adjetivos se entiende que es la ley común, como porque dicha clase de leyes representan la regla general en nuestro Código Político, constituyendo las leyes interpretativas, las orgánicas constitucionales y las de quórum calificado la excepción dentro de la denominación genérica de ley" ${ }^{14}$.

En este sentido, cabe concluir que la adquisición del DAA no está sujeta a ley de quórum calificado y que el texto normativo que la ha regulado ha sido el $C A$.

Sobre el modo de adquirir el DAA, el TC también ha resuelto:

"El derecho a desarrollar una actividad económica haciendo uso de un derecho de aprovechamiento de aguas, supone necesariamente la adquisición previa de ese derecho. Quien no lo ha obtenido de acuerdo con los procedimientos y requisitos que establece la legislación, no puede invocar un supuesto derecho a ejercer actividades económicas a través de él”"15.

Así, y de conformidad al art. 140 y siguientes del $C A$, se regula un procedimiento concesional especial para la constitución de un DAA, el que

\footnotetext{
${ }^{12}$ Silva (2018), p. 19.

${ }^{13}$ S. Q. L. (2009), considerando 7..

${ }^{14}$ Grupo Cámara de Diputados de Chile (1997), considerando 10. ${ }^{\circ}$.

${ }^{15}$ H. L. y otros (2006), considerando 21. ${ }^{\circ}$.
} 
se inicia con una solicitud y culmina con la dictación de una resolución administrativa ${ }^{16}$. Estos derechos, a diferencia de los derechos reales regulados en el derecho común, nacen ex novo a la vida jurídica, sin que a su respecto exista un derecho de propiedad del que procedan o se escindan. Esta característica es crucial para efectos de contemplar a su respecto un régimen exorbitante al derecho común para regularlos.

Sin embargo, y como expresamente lo dispone el art. 21 del $C A$ :

"La transferencia, transmisión y la adquisición o pérdida por prescripción de los derechos de aprovechamiento se efectuará con arreglo a las disposiciones del Código Civil, salvo en cuanto estén modificadas por el presente Código".

Por tanto, el DAA puede adquirirse por prescripción. Como sugieren Alberto Guzmán y Ernesto Ravera:

"Este modo de adquirir no es nuevo en materia de aguas. Ya en el Código de 1951 se establecía en el artículo 248 la posibilidad de adquirir derechos sobre las aguas, estableciendo un plazo de 5 o de 15 años, según se tratara de prescripción ordinaria o extraordinaria"17.

En este caso, la posesión no se radica sobre las aguas comprendidas en una fuente natural de abastecimiento. Las aguas son bienes nacionales de uso público y como tales son insusceptibles de apropiación privada, atendido su carácter de inembargables e incomerciables. Lo que se posee es un DAA. Para ello, deben concurrir los mismos requisitos que en materia civil. Así, tratándose de derechos reales sobre inmuebles, para poseer un DAA se requiere de un título inscrito. Pero somos de la opinión que, apreciado el tenor del art. $7 .^{\circ}$ del decreto ley n. ${ }^{\circ} 2603$, la posesión de un DAA requiere, además, que concurra un uso efectivo de las aguas a que se refiere este, ya que dicha ley expresamente señala que se presumirá dueño de las aguas a quien le esté dando un uso efectivo. De forma paralela y haciendo aún más evidente este requerimiento, también puede considerarse que el artículo segundo transitorio exige que el usuario haya cumplido cinco años de uso ininterrumpido, contados desde la fecha en que hubiere comenzado a hacerlo. Como expresa Humberto Santelices:

${ }^{16}$ Por circunstancias excepcionales y de interés general, el Presidente de la República podrá constituir directamente un DAA si existieren dos o más solicitudes sobre las mismas aguas y no hubiere recursos suficientes para satisfacer todos los requerimientos (art. 148 $\operatorname{del} C A)$.

${ }^{17}$ Guzmán y Ravera (1998), pp. 79-80. 
“[...] se consagra el principio de 'uso efectivo del agua' ya en el D.L. 2.603 de 1979, principio que recoge con toda crudeza ('caudal legítimamente aprovechado') el artículo 309 del Código de 1981, no obstante las imperfecciones que pueda reconocerse tanto en su interpretación cuanto en su aplicación, y que adicionalmente, constituye exigencia fundamental ('uso ininterrumpido') de la regularización consagrada en el artículo $2^{\circ}$ transitorio del $C A$ de $1981^{\prime \prime}$.

Ello también se justifica en que:

"La prescripción en materia de aguas permite no sólo adquirir un derecho de aprovechamiento, sino también otorga la forma de ejercer ese derecho de aprovechamiento" ${ }^{19}$.

Los DAA se adquieren por prescripción en el modo y la forma en que se han venido utilizando, esto es, consuntiva o no consuntivamente, de forma permanente o eventual, según lo disponen los arts. 313 núm. 3 y 312 núm. 5 del $C A$. Por ello, a diferencia del modelo del Código Civil, y dado que en materia de aguas los hechos son los que informan el derecho, el requisito del uso efectivo se incorpora en la posesión. No puede poseerse un DAA si no es por medio de su ejercicio, el que se efectúa a través de actos útiles que implican el aprovechamiento de las aguas, es decir, la separación de estas de su fuente natural de abastecimiento ${ }^{20}$. El argumento de texto para sostener esta afirmación lo encontramos en el art. $9 .^{\circ}$ del $C A$ que dispone: "El que goza de un derecho de aprovechamiento puede hacer, a su costa, las obras indispensables para ejercitarlo", de donde se desprende que son actos materiales los que conducen al ejercicio del derecho. Del mismo modo, Sergio Rossel refuerza esta idea al decir:

"Como la posesión es un hecho constituido precisamente por el ejercicio del derecho como si se gozara de él, se comprende que debe comenzar con estos actos materiales para los cuales justamente se inicia el ejercicio del derecho" ${ }^{21}$.

Esta circunstancia ha sido corroborada por la jurisprudencia, la que para estos efectos ha resuelto:

\footnotetext{
${ }^{18}$ Santelices (2009), p. 30.

${ }^{19}$ Guzmán y Ravera (1998), p. 84.

${ }^{20}$ Op. cit., p. 89.

${ }^{21}$ Rossel (1960), p. 200.
} 
"[...] en lo que atañe a los derechos de aprovechamiento de aguas, ésta contiene un estatuto especial y excepcional, pues se aparta del principio establecido en el artículo 2505 del Código Civil, desde el momento que el conflicto de intereses que puede plantearse entre un poseedor inscrito de los derechos de aprovechamiento de aguas y uno, que sin tenerlos acogidos al sistema de la propiedad registral los utiliza, es decir, ejerce los actos posesorios inherentes a dicho aprovechamiento como si fuera dueño y titular de los mismos, sin violencia, clandestinidad ni reconocimiento de dominio ajeno, se soluciona privilegiando los intereses del poseedor material por sobre los del poseedor inscrito [...]"22.

\section{La facultad de uso y goce de las aguas ha quedado determinada por la ley}

De conformidad con el art. $6 .^{\circ}$ inciso $1 .^{\circ}$ del $C A$, y siguiendo de cerca las categorías civilistas: "El derecho de aprovechamiento es un derecho real que recae sobre las aguas y consiste en el uso y goce de ellas" ${ }^{23}$. Como puede desprenderse de esta disposición, el DAA se ha definido como un derecho real específico ${ }^{24}$. Es más, de esta definición de matices civiles podría sostenerse que constituye un usufructo constituido sobre un bien de dominio público. En el derecho chileno, el derecho privativo para extraer las aguas nace generalmente ex novo, no existiendo con anterioridad a su creación ${ }^{25}$. Por lo tanto, el DAA no puede definirse como un desmembramiento de las facultades del dominio ejercidas por la Administración, como si se tratara de un "usufructo", sujeto al dominio público estatal.

Siendo las aguas un bien nacional de uso público, a su respecto solo cabe un uso general o común y un uso privativo sobre ellas. No es posible configurar la hipótesis de goce ni el de disposición sobre las aguas contenidas en su fuente natural de abastecimiento. En este sentido, el TC ha resuelto:

${ }^{22}$ Sucesión P. H. con Dirección General de Aguas Cuarta Región (2013), considerando 10..

${ }^{23}$ Hacemos presente que las aguas solo pueden usarse. La facultad de goce respecto al recurso no es concebible jurídicamente. Las aguas son insusceptibles de apropiación privada y de ellas no se pueden obtener réditos civiles.

${ }^{24}$ Guzmán y Ravera (1998), p. 35.

${ }^{25}$ Excepcionalmente, la CPR también ampara los derechos de aprovechamiento reconocidos por la ley (art. 19 núm. 24 inciso 11). Ello hace referencia a los usos inmemoriales que se venían ejerciendo con anterioridad a la entrada en vigor del $C A$. En estos casos, el procedimiento de regularización no los crea, sino que solo los reconoce en la medida en que se cumplan con los requisitos previstos en el artículo segundo transitorio del $C A$. 
“[...] Asimismo, estos son bienes cuyo uso pertenece a todos los habitantes; son bienes sobre los cuales no hay propiedad sino uso. Dicho uso puede ser común o especial. El uso común significa que corresponde en general a todos, aunque se haga individualmente. Dicho uso es anónimo, temporal y no requiere título alguno. [...] El uso privativo, por su parte, implica que la autoridad encargada de su administración entrega por actos específicos la ocupación del bien, temporalmente con un propósito de interés público, generalmente a título oneroso a un particular, quien puede excluir al resto de las personas que accedan a él. El uso privativo implica un uso exclusivo y excluyente del bien. Por eso, exige un título habilitante, que puede ser el permiso o la concesión"26.

Si bien esta sentencia expresa que el uso sobre los bienes nacionales de uso público es específico, temporal y generalmente a título oneroso, cabe señalar que, con respecto al DAA, este se entrega de manera gratuita a su titular y su uso es indefinido y perpetuo.

Atendido a que el constituyente no ha establecido el uso efectivo de las aguas ni ha dispuesto su destinación específica, el legislador ha determinado:

"Una total libertad para el uso del agua a que se tiene derecho y los particulares pueden destinar las aguas a las finalidades o tipos de uso que deseen" ${ }^{27}$.

A este respecto, a pesar de que el art. 140 núm. 2 del $C A$ dispone que el solicitante de un DAA debe señalar el uso que le dará a las aguas requeridas, el art. 149 inciso final, agrega:

"El derecho de aprovechamiento constituido [...], no quedará en modo alguno condicionado a un determinado uso y su titular o los sucesores en el dominio a cualquier título podrán destinarlo a los fines que estimen pertinentes”.

Sin embargo, esta norma debe ser matizada y, en consecuencia, interpretarse de manera armónica con el resto del ordenamiento jurídico. Así, en virtud del art. 149 núm. 7 del $C A$, introducido por la Ley n. ${ }^{\circ} 20017$, de 2005 , el acto administrativo en cuya virtud se constituye el DAA podría incorporar otras especificaciones técnicas relacionadas con la naturaleza

\footnotetext{
${ }^{26}$ W. G. (2008), considerando 33. ${ }^{\circ}$.

${ }^{27}$ Vergara (1998), p. 269.
} 
especial del respectivo derecho y las modalidades que lo afecten, con el objetivo de conservar el ambiente o proteger derechos de terceros.

Sin perjuicio de la excepción anterior, esta libertad de uso también se concede para el "no uso" de las aguas. Pero a contar del año 2005 se estableció el pago de una patente por su no uso (art. 129 bis 4 y siguientes del $C A$ ) que grava a aquel titular de DAA que no tenga construidas las obras suficientes y aptas para captar las aguas y restituirlas, en su caso ${ }^{28}$. En este sentido, el TC ha resuelto:

"Que, como punto de partida, afirmamos que la patente por no uso de aguas es un tributo, con independencia de la denominación de 'patente' que utilice la ley. [...] En primer lugar, es el pago coactivo de una suma de dinero. En segundo lugar, no hay una contraprestación asociada al pago. Finalmente, su pago se destina a solventar gastos generales y no de un supuesto bien o servicio específico que lo justifique [...] Que, sin perjuicio de lo anterior, el Código de Aguas hace referencia a ellas como un tributo en el artículo 129 bis 12, inciso primero, en relación con las atribuciones de la Tesorería General de la República para el cobro de las patentes no pagadas" 29 .

De esta forma, a partir del año 2005, el no uso de las aguas se encuentra gravado con un tributo. Ello, tiene especiales consecuencias negativas para el mantenimiento de usos ecológicos o ambientales de las aguas, puesto que la legislación de aguas al exigir del usuario la existencia de obras necesarias y aptas para captar las aguas, ha desincentivado su uso in situ por medio del establecimiento de esta patente.

\section{La protección de su contenido esencial}

De conformidad a lo dispuesto en el art. 19 núm. 26 de la $C P R$ :

"La seguridad de que los preceptos legales que por mandato de la Constitución regulen o complementen las garantías que ésta establece o que las limiten en los casos en que ella lo autoriza, no podrán afectar los derechos en su esencia, ni imponer condiciones, tributos o requisitos que impidan su libre ejercicio".

${ }^{28}$ Como refuerza MEza (2014), p. 51: “[...] la ley establece un criterio objetivo para la determinación de los derechos no utilizados, tomando en consideración básicamente la existencia o no de infraestructuras de aprovechamiento".

${ }^{29}$ Agrícola San Juan de Huinca Ltda. (2016), considerandos $12 .^{\circ}$ a $14 .{ }^{\circ}$. 
De la disposición transcrita se desprende que el mandato al legislador para regular o complementar el DAA supone la no afectación de su núcleo esencial. Para determinar qué es el núcleo esencial del derecho, María Pía Silva nos indica:

"La esencia del derecho de propiedad se encuentra en la existencia y vigencia tanto del derecho de dominio mismo, como en la de sus facultades inherentes y también en la de sus atributos. Los atributos se refieren al carácter absoluto de la propiedad, porque se ejerce respecto de todos; a que ésta es real, en cuanto se tiene sobre una cosa sin respecto de determinada persona; exclusivo, porque sólo pertenece al dueño; perpetuo, ya que termina con su fallecimiento y, en fin, inviolable, porque sólo puede privarse de ella conforme a la Constitución y la ley" ${ }^{30}$.

A este respecto, el TC ha agregado:

"Un derecho es afectado en su 'esencia' cuando se le priva de aquello que le es consustancial de manera tal que deja de ser reconocible. Asimismo [...] se impide su libre ejercicio en aquellos casos en que el legislador lo somete a exigencias que lo hacen irrealizable, lo entraban más allá de lo razonable o lo privan de tutela jurídica" ${ }^{31}$.

A partir de las consideraciones anteriores podemos colegir que el núcleo esencial del DAA se traduce, justamente, en ser un derecho indefinido en el tiempo; de carácter patrimonial y ejercitable por las acciones dispuestas en la $C P R$ y en las leyes; exclusivo y permanente; definido en relación con su cuantía; tipificado de manera abstracta, es decir, no afectado por su destinación a un uso determinado; y establecido de manera autónoma, es decir, independiente del inmueble al que esté destinado.

Bajo estas consideraciones sobre la protección del núcleo esencial del DAA, a primera vista podría sostenerse que el legislador se encontraría impedido de establecer un límite temporal a su respecto o sujetarlo a un uso específico, a menos que la propia Carta Fundamental lo mandatase. Por este motivo, la ley no contempla ninguna causal de caducidad o de extinción de los derechos de aprovechamiento por su no uso. Estos son otorgados indefinidamente a su titular y, por el hecho de estar subsumidos en el estatuto de la propiedad recogida en la $C P R$, se entiende que son de-

${ }^{30}$ Silva (2018), p. 20.

${ }^{31}$ H. L. y otros (2006), considerando 20.. 
rechos absolutos, exclusivos y perpetuos ${ }^{32}$. Sin embargo, hemos sostenido que el establecimiento de causales de extinción o de caducidad del DAA constituye una facultad privativa del legislador, puesto que los términos de la reserva legal que el constituyente efectúa en el art. 19 núm. 24 inciso final de la $C P R$, son lo suficientemente amplios como para que el legislador pueda modular dichas causales a partir de los intereses generales que motivan la publificación de las aguas ${ }^{33}$. Es más, como el elemento teleológico de la publificación del recurso supone una noción variable de acuerdo con la evolución de los intereses generales, podemos observar que, a partir del año 2005, la legislación de aguas ha experimentado cambios profundos que la llevan a consolidar legislativamente el concepto del uso efectivo de las aguas al incorporar la patente por no uso de estas. Dicho concepto es la base de una causal de extinción de los DAA.

\section{Cualquier limitación al derecho de aprovechamiento u obligación impuesta a su ejercicio debe ser prevista por la ley $y$ en consideración a la función social de la propiedad}

Esto último significa que las restricciones solo pueden basarse en los intereses generales de la nación, la utilidad y salubridad pública, la seguridad nacional o la conservación del patrimonio ambiental. En este sentido, el $\mathrm{TC}$ ha resuelto:

"La facultad del legislador de establecer las limitaciones y obligaciones que deriven de la función social de la propiedad se aplica, prima facie, a todas las clases y especies de propiedad, incluyendo, la que se refiere a derechos constituidos sobre aguas. La naturaleza del derecho de propiedad sobre las aguas no permite sostener que esté exento de restricciones, cargas o limitaciones debido a

${ }^{32}$ Sin perjuicio de lo anterior, debe tenerse presente que, como todo derecho, este presenta ciertas limitaciones intrínsecas, similares a lo que ocurre con la propia definición de dominio en el art. 582 del Código Civil. Por ejemplo, el art. 62 del CA: "Si la explotación de aguas subterráneas por algunos usuarios afectare la sustentabilidad del acuífero u ocasionare perjuicios a los otros titulares de derechos, la Dirección General de Aguas, de oficio o a petición de uno o más afectados, podrá establecer la reducción temporal del ejercicio de los derechos de aprovechamiento, a prorrata de ellos, mediante resolución fundada. // Esta medida quedará sin efecto cuando los solicitantes reconsideren su petición o cuando a juicio de dicha Dirección hubieren cesado las causas que la originaron”. En este sentido, la DGA puede reducir temporal y proporcionalmente el ejercicio de los DAA, en la forma y con los requisitos que establece la ley.

${ }^{33}$ Para estos efectos, puede consultarse el Informe de la Comisión de Agricultura del Senado de fecha 27 de marzo de 2020 recaído en el Boletín 7543-12, sobre reforma al Código de Aguas. 
la función social de la propiedad. El derecho de propiedad, en general y en particular el derecho de propiedad sobre las aguas reconoce como límite su función social, en virtud de la cual se pueden establecer limitaciones específicas al mismo"34.

Una limitación que admite el $C A$ a la creación de los DAA está dada por el establecimiento de modalidades específicas en su constitución, como ya hemos indicado al dar cuenta de lo dispuesto en el art. 149 núm. 7. Estas limitaciones se han traducido en la imposición de planes de alerta temprana en los $\mathrm{DAA}^{35}$. En virtud de esta medida, un DAA determinado puede nacer condicionado o sujeto a la eventualidad de ser reducido o suspendido en su extracción, en caso de que se verifique un determinado grado de afectación o de impacto negativo en su área de influencia. Lo anterior, para proteger los derechos de terceros del área o para conservar el ambiente. Cabe señalar que, por el motivo indicado, esta limitación no opera respecto de todos los DAA, ya que es una facultad discrecional de la DGA y solo se contempla en los nuevos que surgieron a partir de la reforma del año 2005 en acuíferos sometidos a una alta presión extractiva.

Asimismo, con ocasión de la creación de los derechos subterráneos, a partir del año 2005 se ha dispuesto:

“[...] procederá la constitución de derechos de aprovechamiento sobre aguas subterráneas, siempre que la explotación del respectivo acuífero sea la apropiada para su conservación y protección en el largo plazo [...]” (art. 147 bis inciso final del $C A$ ).

En el caso de las aguas subterráneas, la Administración ya no solo tendrá en cuenta la disponibilidad del acuífero y el perjuicio de terceros, sino, también, su sustentabilidad, pudiendo denegar aquellas solicitudes que no satisfagan esta cualidad.

Por último, la Administración también podrá:

"Limitar el caudal de una solicitud de derechos de aprovechamiento, si manifiestamente no hubiera equivalencia entre la cantidad

${ }^{34}$ S. Q. L. (2009), considerando 3. ${ }^{\circ}$.

${ }^{35}$ Un plan de alerta temprana consiste en: “[...] una herramienta de gestión, en este caso hídrica, que tiene como objetivo realizar el pronóstico, seguimiento, evaluación y verificación de los efectos o impactos previstos al momento de otorgar un derecho de aprovechamiento de agua[s]. Todo esto por medio de la definición de indicadores con sus umbrales respectivos que permitan evaluar oportunamente en el tiempo el grado de afección o impacto en el área de influencia del derecho, para corregir en los casos que se generarse [sic] una afección o impacto reduciendo, ajustando o suspendiendo el ejercicio del derecho otorgado”. DGA (2012), p. 5. 
de agua que se necesita extraer, atendidos los fines invocados por el peticionario en la memoria explicativa [...]" (art. 147 bis inciso segundo del $C A$ ).

De este modo, se evita el uso abusivo o bien especulativo que un solicitante quiera realizar. El peticionario deberá demostrar a la DGA que el uso solicitado se cohonesta con las cantidades dispuestas para ello en una tabla de equivalencias entre caudales de agua y usos que refleja las prácticas habituales en el país ${ }^{36}$. En caso de que no exista concordancia entre el uso y la cantidad de agua solicitada, la DGA podrá disponer una rebaja en el caudal a otorgar.

\section{Cualquier privación o expropiación de los derechos de aprovechamiento}

(o una parte de ellos o de sus facultades o atributos)

solo podrá hacerse por una ley, general o especial, que autorice la expropiación por causa de utilidad pública

o de interés nacional, previamente calificada por el legislador

La expropiación de un DAA se sujeta a las reglas generales. Al respecto, conviene señalar:

"Solo se puede privar a una persona de alguno de sus bienes o de alguna de sus facultades o atributos esenciales si existe un interés público que lo justifique; en otros términos, no puede ser un acto arbitrario sino justificado en las causales de 'utilidad pública' o interés nacional" ${ }^{37}$.

Por su parte, el art. 27 del $C A$ dispone:

"Cuando sea necesario disponer la expropiación de derechos de aprovechamiento para satisfacer menesteres domésticos de una población por no existir otros medios para obtener el agua, deberá dejarse al expropiado la necesaria para iguales fines".

Con ello, por un lado se deja de manifiesto que la privación de un DAA solo procede en caso de utilidad pública ${ }^{38} \mathrm{y}$, por otro, se deja ver una excepción

${ }^{36}$ La tabla de equivalencias se encuentra en el decreto supremo 743/2005, del Ministerio de Obras Públicas.

${ }^{37}$ Quezada (2018), p. 96.

${ }^{38}$ La jurisprudencia constitucional ha señalado: “[...] la utilidad es 'pública' por variadas razones. Primero, porque su objeto es permitir, de modo principal o subsidiario, el ejercicio de derechos fundamentales de los ciudadanos (salud, educación, movilización, vivienda, cultura, adecuadas condiciones de vida y salubridad)". J. C. (2014), considerando $21 .^{\circ}$. 
al régimen común de la expropiación. Trátase este del único caso en la legislación en que existe un límite al desposeimiento de un bien. Por regla general, se pueden expropiar toda clase de bienes y el único requisito para que proceda la privación es que se indemnice del perjuicio efectivamente causado al expropiado. Sin embargo, en este caso, no se pueden desposeer todas las aguas, puesto que deberá dejarse la necesaria para suplir los menesteres domésticos de aquel que fue privado. Observamos aquí que se releva la clave de protección del uso del consumo humano, a pesar de que la legislación no contenga ninguna norma que priorice este uso en su otorgamiento, en su reducción proporcional (hipótesis del art. $62 \mathrm{del} C A$ ) o en su redistribución por causa de sequía (en el caso previsto en el art. $314 \mathrm{del} C A$ ).

Otra vez estamos en presencia de una fractura que se produce al régimen del derecho común. En este caso, porque la utilidad pública que subyace la publificación del recurso, impide la aplicación estricta de las normas comunes con ocasión de la protección del consumo humano y doméstico. Bajo esta lógica, podríamos asumir que el DAA se encuentra a priori afectado al consumo humano y que no está dispuesto, como otros bienes, a su libre circulación. Asimismo, a idéntica conclusión llegamos si tenemos en consideración el art. 147 bis inciso tercero del $C A$, que dispone:

"[...] cuando sea necesario reservar el recurso para el abastecimiento de la población por no existir otros medios para obtener el agua, [...] el Presidente de la República podrá, mediante decreto fundado, con informe de la Dirección General de Aguas, disponer la denegación parcial de una petición de derecho de aprovechamiento".

Si bien en este caso solo existe una mera expectativa, lo que observamos es que a partir del año 2005 se reincorpora en la legislación una prioridad para la constitución de DAA con la finalidad del consumo humano.

\section{La Constitución solo permite al legislador el establecimiento} de restricciones especiales al ejercicio del derecho de propiedad fundadas en la protección al ambiente

Sobre esta materia, el TC ha señalado:

"La propia Carta Fundamental señala, en el numeral $8^{\circ}$ de su artículo 19, que es deber del Estado velar porque el derecho a vivir en un medio ambiente libre de contaminación no sea afectado, en tanto que el numeral $24^{\circ}$ del mismo artículo entiende que la función social de la propiedad comprende la preservación del patrimonio ambiental, dentro de la cual cabe la conservación de los 
caudales de aguas. De todo lo anterior deriva el deber del Estado de adoptar todas las medidas para evitar su agotamiento, en conformidad, además con el artículo $2^{\circ}$, letra b), de la Ley $\mathrm{N}^{\circ} 19.300$, sobre Bases Generales del Medio Ambiente"39.

A este respecto, podemos señalar que la principal restricción específica impuesta a los DAA constituidos a partir del año 2005, se encuentra en el respeto a un caudal ecológico. Así, el art. 129 bis 1 del $C A$, dispone:

"Al constituir los derechos de aprovechamiento de aguas, la Dirección General de Aguas velará por la preservación de la naturaleza y la protección del medio ambiente, debiendo para ello establecer un caudal ecológico mínimo, el cual sólo afectará a los nuevos derechos que se constituyan, para lo cual deberá considerar también las condiciones naturales pertinentes para cada fuente superficial".

Esta figura, más que una restricción específica al ejercicio del DAA, supone una limitación en su otorgamiento, puesto que disminuye su disponibilidad. De este modo, y como opina Camila Boettiger:

"En la práctica, la carga de respetar el paso del caudal ecológico en la fuente se traspasa a las organizaciones de usuarios, y tomando en consideración que pueden existir usuarios con y otros sin esta limitante, es posible cuestionarse si estas organizaciones diferencian en la realidad, en el reparto de las aguas disponibles, la limitación del caudal a determinados usuarios" ${ }^{40}$.

Podemos apreciar que se trata de una medida que está establecida en relación con el DAA y no a nivel de fuente de abastecimiento, lo que dificulta no solo su aplicación efectiva por las organizaciones de usuarios, sino que está lejos de estar concebida en protección de la fuente natural de abastecimiento. Y como ha sostenido Tatiana Celume:

"Esta cuestión responde, en general, a la formulación privatista del Derecho de Aguas chileno, especialmente en lo que se refiere a la gestión de los recursos hídricos" ${ }^{\prime 1}$.

Otra restricción específica al DAA está constituida por la reducción proporcional a su ejercicio en caso que la extracción efectuada en una

${ }^{39}$ S. Q. L. (2009), considerando 6. ${ }^{\circ}$.

${ }^{40}$ Boettiger (2013), p. 11.

${ }^{41}$ Celume (2013), p. 318. 
fuente subterránea por algún usuario afecte la sustentabilidad del acuífero o perjudique a terceros (art. $62 \mathrm{del} C A$ ). Sobre la afectación a terceros, esta es la regla general en el $C A$. Sin embargo, la afectación a la sustentabilidad fue recién incorporada en virtud de la Ley n. ${ }^{\circ} 21064$, de 2018. Si bien el $C A$ no determina el sentido y alcance del vocablo 'sustentabilidad', esta noción debemos concordarla con el art. 147 bis inciso final, que dispone que la explotación de los acuíferos debe ser "[...] la apropiada para su conservación y protección en el largo plazo". De este modo, serán sostenibles aquellas extracciones que no ocasionen un desbalance importante o sostenido entre la recarga y la descarga de un acuífero. Como refuerza Camilo Larraín:

"La explotación de un acuífero tiene características muy distintas a la de las aguas superficiales, al menos las corrientes. En efecto, la explotación tiene que ser autorizada de tal manera que no haya una sobreexplotación del mismo, que no vaya más allá de la renovación del mismo, es decir, lo que en concepto de la DGA es una explotación sustentable" ${ }^{42}$.

En caso contrario, la DGA podrá limitar a prorrata las extracciones de dicha fuente, y mantener tal medida mientras no cesen las causas que le dieron origen.

\section{El ESTATUTO CIVIL DE LA PROPIEDAD Y EL DAA}

Sobre la consideración de que los DAA están sometidos al régimen de la propiedad raíz inscrita (art. $121 \operatorname{del} C A$ ), a continuación analizaremos qué consecuencias derivan de ello tanto en su constitución como en su posesión y su transferibilidad.

\section{Sobre la constitución del DAA}

El $C A$ aplica a un derecho que nace ex novo, las categorías de la propiedad inscrita reguladas en el derecho común. El sometimiento a las reglas de la propiedad inscrita fue propuesto por el art. $7^{\circ}$ de la Ley n. ${ }^{\circ} 2139$, de 1908, sobre Asociaciones de Canalistas que disponía:

"Son aplicables a los regadores de agua establecidos conforme a esta lei todas las disposiciones que rijan la propiedad inscrita $\mathrm{i}$ especialmente la de los títulos vi i viI del libro II del Código Civil”.

${ }^{42}$ Larraín (2016), p. 164. 
El $C A$ de 1951, continuando con tal tradición, señalaba en su art. 244:

"Se aplicará a los derechos de aprovechamiento [...], inscritos en los Registros de Aguas de los Conservadores de Bienes Raíces con posterioridad a la fecha en que se encuentre en vigencia la presente ley, todas las disposiciones que rigen la propiedad raíz inscrita en cuanto no hayan sido modificadas por el presente Código. // Se continuará aplicando también esas disposiciones a los derechos de agua inscritos en conformidad a la ley N.o 2,139, sobre Asociaciones de Canalistas [...]”.

Como destaca Sergio Rossel:

"De esto se desprende que en materia de aguas tal como tratándose de bienes raíces sujetos al régimen de la inscripción conservatoria, ésta es garantía y prueba de la posesión” ${ }^{43}$.

El $C A$ de 1981 no pretendió alterar la regla y dispuso en su art. 121:

"A los derechos de aprovechamiento inscritos en los Registros de Aguas de los Conservadores de Bienes Raíces, se les aplicarán todas las disposiciones que rijan la propiedad raíz inscrita, en cuanto no hayan sido modificadas por el presente Código".

Sin embargo, a su vez, dispuso en su art. 20:

"El derecho de aprovechamiento se constituye originariamente por acto de autoridad. La posesión de los derechos así constituidos se adquiere por la competente inscripción" ${ }^{44}$.

La disposición del $C A$ vigente parece separar en dos momentos diversos la posesión del DAA y su adquisición (dominio). En otras palabras, esta norma dispone que el derecho se constituye por medio de la resolución constitutiva de la DGA, pero que la posesión sobre este derecho recién se

${ }^{43}$ Rossel (1960), p. 197.

${ }^{44}$ Esta norma constituye una innovación respecto del $C A$ de 1951, que disponía, en su art. 238: "La tradición de los derechos de aprovechamiento que deban inscribirse en conformidad a los dos artículos siguientes se efectuará por la inscripción del título en el Registro de Aguas del Conservador de Bienes Raíces. // De la misma manera se efectuará la constitución y la tradición de los derechos reales a que se refieren esos mismos preceptos". En virtud de esta norma, el DAA se constituía y se transfería con su competente inscripción conservatoria. 
adquiere con su inscripción en el Registro de Propiedad del Conservador de Bienes Raíces competente, pudiendo adquirirse el dominio del DAA sin necesidad de que opere la inscripción y, por ende, su posesión. En consecuencia, si se pretendiese que las inscripciones de los títulos de aguas "fuesen más que nada una garantía y prueba de la posesión" ${ }^{45}$, entonces, la inscripción debería constituirse como un requisito de existencia del derecho y este no podría existir sin mediar la competente inscripción.

Es en este punto donde podemos observar que ciertas reglas del derecho común parecen no cohonestarse con la regulación administrativa que corresponde al DAA. Los derechos reales distintos del dominio regulados en la legislación civil presuponen la existencia de un dominio anterior. Es así como el usufructo, por ejemplo, se plantea como un derecho real limitativo del dominio. El DAA, por su parte, constituye un derecho $e x$ novo, un derecho que no nace sujeto o a partir de un derecho de dominio preexistente. El intento de aplicar sistemáticamente las reglas del derecho civil a las categorías administrativas en este caso demuestra ciertas fricciones con sus instituciones. Para subsanar estos roces, la doctrina especializada ha sostenido que la competente inscripción a que se alude en el art. 20, tiene "un rol de certeza jurídica, pues la inscripción no es el

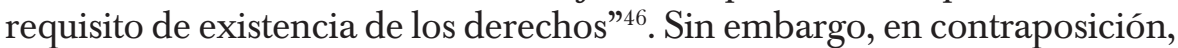
la jurisprudencia constitucional ha señalado que la inscripción del DAA es un requisito de existencia. En este sentido, el TC ha resuelto:

“[...] antes de dictarse el acto constitutivo del derecho de aguas, de reducirse éste a escritura pública e inscribirse en el competente registro, el derecho de aprovechamiento no ha nacido al mundo jurídico, pues precisamente emerge, originariamente, en virtud de la mencionada resolución y su competente inscripción" ${ }^{47}$.

Podemos apreciar que, por más que pretenda someterse el derecho de aguas al estatuto de la propiedad inscrita, esta subsunción plantea ciertas dificultades que parecen complejas de solucionar, especialmente por el carácter originario del DAA. El hecho de que en el derecho de aguas se separe la posesión del dominio en dos instancias diferentes, puede conducir a que el dueño (no inscrito, por tanto, no poseedor) no pueda ejercer las acciones posesorias mientras no inscriba su derecho. Sin embargo, una consecuencia derechamente observable en materia de aguas es la posibilidad de que el titular de DAA no inscritos pueda especular con ellos. Lo

\footnotetext{
${ }^{45}$ Vergara (1998), p. 325.

${ }^{46}$ Op. cit., p. 326.

${ }^{47}$ Grupo Cámara de Diputados de Chile (1997), considerando 8. .
} 
anterior, se verifica toda vez que la patente por no uso de las aguas, para efectos de proceder al remate de estos títulos, solo puede ejercerse sobre los DAA inscritos (art. 129 bis $14 \operatorname{del} C A$ ). Como una medida de eludir su aplicación, los titulares que desean especular con sus títulos esperando una situación de mayor estrés hídrico para desprenderse de ellos, evitan, en el intertanto, practicar la inscripción de su DAA en el Registro de Propiedad del Conservador de Bienes Raíces competente. Esta dualidad de dominio y posesión permite y avala este comportamiento elusivo. Creemos que lo más apropiado sería reconocer el carácter constitutivo de la inscripción registral. A pesar de ello, creemos que este es un problema que escapa de la órbita del derecho común. Torcer los márgenes del derecho civil para hacerlo aplicable a las categorías administrativas, como en este caso, solo redunda en una confusión innecesaria.

\section{La propiedad sobre los usos de las aguas}

La CPR contempla, asimismo, la protección de otra forma de DAA. Nos referimos a los derechos "reconocidos" que quedan amparados por la propietarización constitucional del art. $19 \mathrm{n}^{\circ} .24$ inciso 11 de la $C P R$. Estos tienen su fundamento en el principio de uso efectivo de las aguas consagrado legalmente en el inciso $2 .^{\circ}$ del ya citado art. $7 .^{\circ}$ del decreto ley n. ${ }^{\circ} 2603$, de 1979, que dispone: "[...] se presumirá que es titular del derecho de aprovechamiento quien se encuentre actualmente haciendo uso efectivo del agua". Se trata de una situación de hecho a la que el ordenamiento jurídico ha ampliado su manto protector a través de la propiedad garantizada en la $C P R$. Estos usos ancestrales están reconocidos por el ordenamiento jurídico aun cuando a su respecto no se haya realizado un procedimiento de regularización. Daniela Rivera ha sostenido que, a través de la regularización, no se crean nuevos DAA. Estos ya existían y solo "se logra consolidar el proceso iniciado con el reconocimiento de usos consuetudinarios de aguas" 48 .

Esta categoría de derechos riñe con las instituciones del derecho civil. El derecho común solo admite la propiedad sobre las cosas corporales y, por excepción, establece una especie de propiedad sobre los derechos (art. 583 del Código Civil). Sin embargo, no hay cabida para sostener que se tiene propiedad sobre ciertos hechos, como son los usos inmemoriales sobre las aguas. Esta extensión o intento de protección civil sobre los hechos desvirtúa las bases sobre las cuales se construye el derecho civil patrimonial. Claramente, el derecho de aguas se sustenta sobre otras consideraciones. En la legislación de aguas, los hechos tienen tanta fuerza vinculante como

${ }^{48}$ Rivera (2013), p. 251. 
las situaciones de derecho, y es por ello que la $C P R$ les extiende su protección. Los usos inmemoriales de las aguas, concebidos como derechos en la lógica del derecho de aguas, son hechos y no pueden ser identificables con el objeto de la propiedad privada. Es más, a su respecto no se configura la libre transferibilidad que supone la transferencia que media por inscripción del título. Esa "propietarización" no responde a los cánones del derecho civil. Con ello, queremos insistir sobre la preocupación de la aplicación sistemática de reglas del derecho común a instituciones que responden a una regulación exorbitante al mismo.

En similar sentido, cabe señalar que la legislación contempla la existencia de DAA por el solo ministerio de la ley o derechos "aconcesionales" ${ }^{49}$. Esta última figura obedece a usos afectados por la propiedad y/o la función $^{50}$. Podemos apreciar así que los usos para la bebida y el consumo doméstico (art. 56 inciso $1 .^{\circ}$ de la $C A$ ) están atados a la propiedad del predio superficial a la vez que se encuentran destinados a un uso específico y se miden de conformidad a la "necesidad" de abastecimiento de agua y al beneficio propio o al perjuicio que ocasionen a otros pozos cavados con la misma finalidad ${ }^{51}$. Por su parte, las aguas del minero (arts. 56 inciso $2 .^{\circ}$ del $C A$ y 110 del Código de Minería) se refieren a usos que están vinculados a la propiedad de la concesión minera respectiva y destinados al uso que

${ }^{49}$ A este respecto, conviene señalar que este reconocimiento se efectúa tanto en aguas superficiales como subterráneas. En aguas superficiales, son derechos constituidos por el solo ministerio de la ley aquellas aguas que la legislación civil, previo a la reforma introducida por la Ley n. ${ }^{\circ} 16640$ consideraba aguas privadas. Sobre esta materia, que excede los propósitos de este trabajo, véase Vergara (1998), pp. 333-337, quien los trata como usos mínimos o limitados.

${ }^{50}$ Como destaca Rivera (2015), pp. 240-241: "Aunque el Código precisa que, fuera de los dos casos previamente mencionados, todo aprovechamiento de aguas subterráneas requerirá la correspondiente concesión, la Ley N 19.657 sobre concesiones de energía geotérmica, incluye otra hipótesis de derecho de aguas subterráneas reconocido por el sólo ministerio de la ley".

${ }^{51} \mathrm{El}$ contenido de este uso ha sido precisado reglamentariamente en el art. 51 del decreto supremo del MOP n. ${ }^{\circ}$ 203/14, disponiendo: "Se entenderá por bebida y uso doméstico, en los términos establecidos en el artículo 56 del Código de Aguas, al aprovechamiento que una persona o una familia hace del agua que ella misma extrae de un pozo, con el fin de utilizarla para satisfacer sus necesidades de bebida, aseo personal y cultivo de productos hortofrutícolas indispensables para su subsistencia, sin fines económicos o comerciales". Como puntualizan Guzmán y Ravera (1996), pp. 15-16: "El derogado artículo 945 del Código Civil, hoy reproducido en el artículo 56, inciso $1^{\circ}$, del Código de aguas, que obliga a cegar pozos cavados en suelo propio para la bebida y uso[s] domésticos, cuando no reportan utilidad que puede compararse con el perjuicio ajeno, tiene como antecedente el Código de las Partidas, que a su vez se inspira en el Derecho Musulmán”. Creemos que se trata de una hipótesis legal que recoge el principio del abuso del derecho. El origen musulmán de la institución nos aclara que estos usos deben ser mínimos y que su medición no es abstracta, sino que se produce de la interrelación con los pozos de otros usuarios aledaños. 
irroguen las labores mineras. Su unidad de medida está condicionada a lo "necesario" para las labores de la concesión. Como conceptualizan Daniela Rivera y Alejandro Vergara:

"Este especialísimo derecho debe entenderse como un uso limitado, autorizado por la legislación, al margen del sistema concesional, de modo excepcional, constreñido a las necesidades del concesionario minero, originando una hipótesis restrictiva" ${ }^{\text {"52. }}$.

Otros usos menores o limitados sobre aguas superficiales son aquellos que reconoce la legislación a los propietarios ribereños sobre las vertientes que nacen, corren y mueren dentro de la misma heredad y sobre los lagos menores no navegables por buques de más de cien toneladas, de conformidad a lo dispuesto en el art. 20 inciso $2 .^{\circ}$ del $C A$. Se trata de los antiguos usos riparianos en el cual el acceso está restringido a los propietarios de los predios ribereños. Como argumenta Gonzalo Arévalo, en todos estos casos:

"Estamos en presencia de casos en que la propiedad del derecho de aprovechamiento va indisolublemente unida al bien raíz en que están situadas las respectivas fuentes naturales" ${ }^{53}$.

Así, en los pozos para la bebida y el consumo doméstico, las vertientes y los lagos menores, el requisito es ser titular del predio ribereño o de aquel en el que se encuentra la fuente natural, mientras que para las aguas del minero se requiere ser titular de las concesiones mineras respectivas. No es posible sostener que estos usos mínimos constituyen una tipología de derechos que está amparada por la propietarización civil de los DAA. Estos usos no son más que extensiones o usos de la propiedad a la que adhieren. Así, el derecho a cavar en suelo propio un pozo o a aprovechar las aguas de una vertiente interior, no puede considerarse aisladamente un derecho a ser reconocido o amparado con independencia de la propiedad a la cual pertenecen o acceden. Lo mismo ocurre con las aguas halladas en labores mineras: este hallazgo está siempre ligado a la propiedad sobre la concesión minera.

Además, cabe señalar que estos usos no constituyen un derecho propiamente tal, ya que no son transferibles, no existe a su respecto la libertad de uso y no están determinados de manera abstracta (en volumen por unidad de tiempo). Se trata de meras autorizaciones legales para acceder

${ }^{52}$ Rivera y Vergara (2015), p. 3.

${ }^{53}$ Arévalo (2011b), p. 173. 
a un aprovechamiento estimado mínimo o necesario según el uso al que están destinadas. Esta suerte de propietarización sobre los usos mínimos no es más que un intento de avasallar categorías exógenas al derecho especial de aguas. En suma, el hecho de que la legislación de aguas regule estas situaciones de hecho como si de derechos autónomos se tratara, no puede constituir una exigencia para el derecho común.

\section{La libre transferibilidad del DAA}

Las características centrales del "mercado de aguas" son la libertad en el uso de las aguas, es decir, que los DAA no quedan condicionados a ningún uso específico, y la separación del agua de la tierra, la que en palabras de Alejandro Vergara significa:

“[Que] el nuevo titular pued[e] utilizar las aguas en cualquier otro sitio de la cuenca, sin perjuicio de las autorizaciones que deberán obtenerse de modo previo" 54 .

$\mathrm{El}$ art. $6 .^{\circ}$ inciso $2 .^{\circ}$ del $C A$ ha dispuesto que el titular del DAA tendrá las facultades de uso, goce y disposición. En efecto, la norma establece:

"Como consecuencia de tenerse la propiedad, es un derecho que [...], es de libre disponibilidad por parte de su titular, incluso para distintos usos" ${ }^{\prime 5}$.

Se consolida así la libre transferibilidad de los DAA en el mercado de aguas, el que ha quedado regulado por las normas del derecho común, por expresa disposición del art. $21 \mathrm{del} C A$. Este dispone:

"La transferencia, transmisión y la adquisición o pérdida por prescripción de los derechos de aprovechamiento se efectuará con arreglo a las disposiciones del Código Civil, salvo en cuanto estén modificadas por el presente Código".

Sobre este punto, Gonzalo Arévalo ha señalado:

“[...] el CA actual está inspirado en un sistema económico de mercado y ha pretendido crear las condiciones que ha creído idóneas para que tal mercado se desarrolle. Es por la razón anterior que

\footnotetext{
${ }^{54}$ Vergara (1998), p. 268.

55 Arévalo (2011c), p 19.
} 
nuestro Derecho de Aguas vigente, retomando, por una parte, algunas instituciones del CA de 1951, fundamentalmente el régimen de propiedad inscrita; y por la inversa, modificando absolutamente el CA de 1969, ha fortalecido y reforzado el régimen del derecho de propiedad sobre el derecho de aprovechamiento de aguas" 56 .

De este modo, una vez constituido, el DAA se incorpora al tráfico jurídico privado gozando de todas las características de un derecho real, esto es, ser un derecho de contenido patrimonial oponible a terceros. Sin embargo, cabe insistir que el DAA es un derecho público subjetivo que nace ex novo de un procedimiento concesional previo, y que solo por opción del legislador se le ha revestido de estos caracteres civilistas una vez ya constituido. Tanto así, que, para algunos autores como Jorge Reyes, el $C A$ "consagra un derecho real de naturaleza civil, esto es, irrevocable, sobre las aguas públicas corrientes" ${ }^{\prime 7}$. Esta misma lógica se mantiene con la legislación actual.

A modo de conclusión, sostenemos que el DAA debe ser concebido desde la perspectiva administrativa y a partir de esta consideración, el régimen que lo regula es exorbitante al derecho común. Baste solo recordar que el DAA configurado en la lógica del $C A$ de 1951, a pesar de ser arrojado al estatuto de la posesión inscrita, presentaba otras características que lo hacían acercarse a la lógica administrativa, tales como, su caducidad y su duración definida en el tiempo (para el caso de las mercedes temporales). Con ello queremos señalar que este derecho no puede ser concebido como una titularidad puramente civil, como un derecho real limitativo del dominio público, no solo porque es discutible la existencia de un dominio público estatal sobre las aguas, sino, también, por las especiales características que se aprecian en él. En este sentido, el DAA es una facultad para usar privativamente las aguas a las que se tiene derecho. No es un derecho que se radique al punto de confundirse con el objeto sobre el que recae (las aguas).

\section{ElEMENTOS POR CONSIDERAR POR UNA PROPUESTA CONSTITUCIONAL}

A continuación, revisaremos ciertas propuestas que redundan en la configuración del DAA, con la finalidad de modificar el objetivo de la publificación del recurso. Creemos que el elemento rector de la afectación del carácter público de las aguas no solo puede concebirse en la reasignación

\footnotetext{
${ }^{56}$ Arévalo (2011a), p. 81.

${ }^{57}$ Reyes (1960), p. 279.
} 
de los usos del agua a aquellos estimados de mayor valor en el mercado ${ }^{58}$. Las demandas ambientales y la necesidad de abastecer a la totalidad de la población con agua para el consumo doméstico son los ejes sobre los cuales debe sustentarse la publificación del recurso hídrico.

Teniendo en consideración que la $C P R$ actual no contiene una reserva constitucional para regular el marco básico concerniente a las aguas y sus usos, proponemos uno que establezca ciertos aspectos mínimos que consideramos relevantes fijar en el ámbito constitucional, por medio de la inclusión de ciertos principios que orienten el posterior desarrollo legislativo. A su vez, creemos necesario que la $C P R$ incorpore una garantía de acceso al agua que esté en línea con las directrices del derecho internacional, que pueda ser tutelada directamente por medio de una acción de protección constitucional, y que, a la vez, provea de las herramientas necesarias para que el legislador pueda hacerla efectiva mediante el establecimiento de una priorización para dicho uso, tanto en el otorgamiento como en la limitación de los DAA. En este apartado desarrollaremos todos estos aspectos.

A diferencia de diversos textos constitucionales latinoamericanos que contienen una especial declaración sobre la naturaleza jurídica de las aguas $^{59}$, el texto chileno renuncia a ello y, tal como lo señalamos, solo efectúa una reserva legal para los bienes nacionales de uso público en su art. 19 núm. 23. Ha correspondido al legislador (mediante el Código Civil y el $C A$ ) otorgar a las aguas el carácter de bien nacional de uso público. En virtud de esta categorización y de aquel mandato otorgado en el art. 19

${ }^{58}$ Como explicita Recabarren (2016), p. 316: “[...] el Derecho de Aguas en ningún caso debe estar configurado sobre la base de la libre explotación de los recursos hídricos por parte de los particulares, sino que, además, debe incorporar los mecanismos necesarios para garantizar un uso y gestión sustentable de las aguas que permita, asimismo, asegurar la protección del medio ambiente, y con ello el respeto y garantía de los derechos humanos que de él dependen. Lo anterior exige la incorporación de figuras que en cierta forma limiten el desarrollo de actividades económicas, como son la norma del uso efectivo y beneficioso; la regla que establece un orden de preferencia en razón de los distintos usos del agua; las disposiciones que reconocen y desarrollan el principio de unidad de cuenca hidrográfica, y las que establecen caudales ecológicos".

${ }^{59}$ Por ejemplo, el art. 12 de la Constitución ecuatoriana de 2008, señala: “[...] El agua constituye patrimonio nacional estratégico de uso público, inalienable, imprescriptible, inembargable y esencial para la vida”. El art. 373.II de la Constitución boliviana, dispone: "Los recursos hídricos en todos sus estados, superficiales y subterráneos, constituyen recursos finitos, vulnerables, estratégicos y cumplen una función social, cultural y ambiental. Estos recursos no podrán ser objeto de apropiaciones privadas y tanto ellos como sus servicios no serán concesionados y están sujetos a un régimen de licencias, registros y autorizaciones conforme a Ley". Y el art. 27 de la Constitución mexicana indica: "La propiedad de las tierras y aguas comprendidas dentro de los límites del territorio nacional, corresponde originariamente a la Nación, la cual ha tenido y tiene el derecho de transmitir el dominio de ellas a los particulares, constituyendo la propiedad privada". 
núm. 24 inciso final de la $C P R$, el legislador ha quedado libre para determinar el contenido de la publificación de las aguas y para ello ha moldeado libremente las características y la extensión de los DAA.

Así, a lo largo del tiempo, el legislador ha ido adoptando diversas definiciones del DAA y con ello ha mudado los motivos que justifican la publificación de las aguas ${ }^{60}$. Lo que ha caracterizado la legislación de aguas en Chile es que no existe ninguna definición constitucional que constriña o le dé ciertas directrices o pautas al legislador para efectos de regular su contenido, y, conforme a ello, se ha dado origen a las más variopintas definiciones de aquellos y a las más diversas justificaciones del carácter público de las aguas ${ }^{61}$. Creemos necesario superar este modelo y que el constituyente establezca un marco conceptual sobre la regulación de las aguas para que luego, por reserva legal, le corresponda al legislador desarrollar el contenido y características del DAA conforme a los principios que la Carta Fundamental reconozca y ampare.

Para estos efectos, en los apartados que siguen proponemos ciertos aspectos basales de dicho nuevo marco regulatorio.

\section{Asignación justificada en el interés público}

En la actualidad y de conformidad a los arts. 22 y 141 inciso segundo del $C A$, los DAA se otorgan toda vez que exista una solicitud legalmente procedente, exista disponibilidad del recurso y no se hayan presentado oposiciones de terceros ${ }^{62}$. Si bien el análisis técnico de la disponibilidad

${ }^{60}$ En este sentido, el art. 595 del Código Civil disponía: "Los ríos y todas las aguas que corren por causes naturales, son bienes nacionales de uso público. // Exceptúense las vertientes que nacen y mueren dentro de una misma heredad: su propiedad, uso y goce pertenecen a los dueños de las riberas, y pasan con éstas a los herederos y demás sucesores de los dueños". LiRa y dE la MAZA (1940), p. 15 señalaban: "De las disposiciones de los artículos 585, 593, 595, 596 y 837 de nuestro Código Civil, se desprende una clasificación de las aguas en tres grupos diferentes: aguas comunes a todos los hombres, aguas nacionales de uso público y aguas de dominio privado". El CA de 1951 contemplaba un sistema concesional bipartito con la existencia de concesiones provisorias y definitivas. Además, establecía un uso específico para los derechos de aprovechamiento provenientes de la merced. Por su parte, el $C A$ de 1969 contemplaba un DAA sujeto a intensas regulaciones por parte de la DGA, especialmente referidas a medidas de redistribución.

${ }^{61}$ Algo similar ocurre en España. Así, para Menéndez (2012), p. 190: “Aplicada a las aguas, la declaración de su naturaleza demanial no es un imperativo constitucional, sino una opción del legislador. Como ha recordado la STC 149/2011, de 28 de septiembre, el artículo $132 \mathrm{CE}$ 'no impone [...] el carácter demanial de las aguas, sino que habilita, en todo lo no contemplado por el mismo, un amplio margen para el diseño del dominio público hidráulico hasta el punto de que la propia demanialización de esta categoría de bienes es una opción del legislador'”.

${ }^{62}$ Así, el inciso $3 .^{\circ}$ del art. 141 del $C A$, dispone: "Si no se presentaren oposiciones dentro del plazo se constituirá el derecho mediante resolución de la Dirección General 
habilita a la Administración para denegar solicitudes, en general la DGA no tiene facultades discrecionales, basadas en el interés público, para rechazar la constitución de un DAA. Una primera excepción a tal formulación se refiere a la imposibilidad de constituir tales derechos en las zonas que corresponden a acuíferos que alimentan vegas y bofedales de las regiones de Tarapacá y Antofagasta (art. 53 inciso $2 .^{\circ}$ del $C A$ ). Otra se encuentra en la posibilidad de que la Administración deniegue parcialmente solicitudes en trámite, creando reservas de aguas. En este sentido, el art. 147 bis inciso $3 .^{\circ}$ del $C A$ dispone:
"Asimismo, cuando sea necesario reservar el recurso para el abaste- cimiento de la población por no existir otros medios para obtener el agua, o bien, tratándose de solicitudes de derechos no consun- tivos y por circunstancias excepcionales y de interés nacional, el Presidente de la República podrá, mediante decreto fundado, con informe de la Dirección General de Aguas, disponer la denegación parcial de una petición de derecho de aprovechamiento".

Sin embargo, en su historia legislativa, la reserva de caudales estuvo orientada a suplir la falta de recurso hídrico para el abastecimiento de la población y para impulsar el desarrollo de actividades productivas relevantes en el contexto regional ${ }^{63}$. Hoy por hoy, la institución de la reserva ha ido mudando tímidamente a un concepto más bien amplio y susceptible de ser utilizado con objetivos de carácter social, tales como el desarrollo local o el turismo de intereses especiales, pero todavía de forma bastante restringida ${ }^{64}$.

de Aguas, siempre que exista disponibilidad del recurso y fuere legalmente procedente. En caso contrario denegará la solicitud".

${ }^{63} \mathrm{El}$ texto original de la indicación del Ejecutivo contenida en el Boletín n. ${ }^{\circ} 876-0928$ y que se incorporó durante su segundo trámite constitucional en el Senado, disponía: "Si previa proposición de la Dirección General de Aguas, el Consejo Regional correspondiente al lugar donde se solicita captar las aguas, resolviere que el derecho de aprovechamiento debe ser denegado o limitado, por ser necesario reservar el recurso al abastecimiento de la población o a determinadas actividades productivas que se califiquen como relevantes para la estrategia de desarrollo regional, por no existir otras alternativas de abastecimiento técnica y económicamente factibles [...]”. Luego, con motivo de las indicaciones que se presentaron durante el segundo trámite constitucional, el Ejecutivo modificó el texto y propuso: “[...] cuando fuere necesario reservar el recurso para el abastecimiento de la población por no existir otros medios para obtener el agua, o bien, por circunstancias excepcionales y de interés general, tratándose de solicitudes de derechos no consuntivos, el Presidente de la República podrá, mediante decreto fundado, con informe de la Dirección General de Aguas, disponer la denegación total o parcial de una petición de derecho de aprovechamiento. [...]”.

${ }^{64} \mathrm{Al}$ menos en dos ocasiones y con la finalidad adicional de fortalecer el desarrollo económico regional, se autorizó a la DGA para denegar ciertas solicitudes de derechos de aprovechamiento no consuntivos pendientes con fundamentos de conservación ambiental, 
A diferencia de los derechos patrimoniales, los derechos públicos subjetivos que nacen ex novo están condicionados a la existencia de ciertos fines que los justifican. En caso de no verificarse este interés público, el derecho no puede nacer a la vida jurídica y, perdiéndose esta finalidad, el derecho está destinado a extinguirse. Estos aspectos no se verifican en el derecho civil, por cuanto en tal órbita los derechos no nacen condicionados a los intereses públicos, son irrevocables y solo pueden perderse por prescripción o por la renuncia. Cabe señalar que aun cuando no esté declarado, ese interés público se encuentra radicado en el otorgamiento y reasignación de los derechos a sus usos de mayor valor. Por ello, el ordenamiento jurídico no ha establecido la caducidad de los DAA que no cumplan dicho objetivo, pero ello no quiere decir que nazcan derechos incondicionados. En otras palabras, es una condición natural de los DAA nacer afectados y sujetos a un interés público.

Creemos que el interés público en su otorgamiento se relaciona con el adecuado equilibrio que debe existir entre las distintas funciones de las aguas (de consumo humano, las ambientales y las productivas), considerando la disponibilidad y la sustentabilidad de la fuente natural de abastecimiento como la distribución de la población y el territorio, asegurando, asimismo, la certeza jurídica que envuelve la creación de estas titularidades. Por ejemplo, al considerar la sostenibilidad ambiental, Ricardo Zuluaga sostiene:

"Se trata de sintetizar o integrar la conservación ambiental y la actividad productiva y económica, en todo el proceso de toma de decisiones $[. . .]^{\prime 65}$.

Como veremos, estimamos necesario reconocer constitucionalmente las distintas funciones de las aguas, protegiendo aquellas que el mercado no contemplará, tales como las funciones ambientales o las de consumo humano. Uno de los objetivos de la publificación es mantener un equilibrio en los usos de las aguas teniendo en consideración las circunstancias naturales de la fuente y la distribución territorial, puesto que la disponibilidad del recurso varía geográficamente, al igual que las necesidades de la población (la que está más concentrada en algunos sitios que otros). Además, es un objetivo de la publificación, cautelar la seguridad jurídica definiendo los DAA. En este sentido, se deben resguardar tanto los derechos constituidos como aquellos usos tradicionales o no extractivos de las

véase HidroAysén S.A con MOP (2017) y Sur Electricidad y Energía S.A. (2017). Asimismo, véase DGA (2009) y DGA (2015).

${ }^{65}$ Zuluaga (2017). 
aguas que no son configurados como DAA, pero que merecen protección en el ordenamiento jurídico. A partir de esta connotación, la identificación del interés público que satisface el otorgamiento de las aguas deriva las demás consecuencias que estudiaremos a continuación.

\section{La protección de la polifuncionalidad de las aguas y el resguardo de su función ambiental}

Este principio deriva de la circunstancia de que las aguas no solo cumplen funciones productivas. También cumplen funciones ambientales y ecosistémicas. Actualmente, el DAA está concebido como un derecho extractivo (y productivo) de las aguas. Los derechos ecológicos o los derechos no extractivos de las aguas no tienen cabida dentro del ordenamiento jurídico. Como señalábamos, aquel usuario que quiera dejar las aguas en el cauce con una finalidad ecológica se ve expuesto al pago de la patente por no uso de las aguas, al no tener las obras construidas para su captación, pero ello no compromete la titularidad del derecho. Lo anterior, tiene su origen en la ausencia de un principio rector constitucional que ampare los usos no extractivos.

Muy vinculado con la necesidad de incorporar los usos no extractivos 44 de las aguas, la $C P R$ debe promover la protección de los usos tradicionales ${ }^{66}$. Estos se refieren a aquellos que efectúan las comunidades indígenas respecto al recurso ${ }^{67}$, y que no están referidos al ejercicio típico del DAA, sino que al uso in situ de ciertas fuentes naturales de abastecimiento, como ríos y vertientes, con la finalidad de destinarlas a la bebida, para el abrevadero y pastoreo de animales, para usos ceremoniales, para la protección de humedales, entre otros que no conllevan la extracción masiva del recurso. Estos usos escapan de la lógica patrimonial privada del DAA tradicional. Se trata de usos mínimos que se encuentran vinculados a la

${ }^{66}$ Hoy por hoy, la legislación contempla de manera excepcional la protección de aquellos acuíferos que alimentan vegas o bofedales de la I y II Región, por medio de su declaración de zona de prohibición para nuevas extracciones. Esta protección es especialísima y muy restrictiva, puesto que tiene una connotación local específica (art. 63 inciso $2 .^{\circ} \operatorname{del} C A$ ).

${ }^{67}$ En este sentido, el art. 64 de la Ley n. ${ }^{\circ}$ 19253, ha establecido: "Se deberá proteger especialmente las aguas de las comunidades aimaras y atacameñas. Serán considerados bienes de propiedad y uso de la Comunidad Indígena establecida por esta ley, las aguas que se encuentren en los terrenos de la comunidad, tales como los ríos, canales, acequias, pozos de agua dulce y vertientes, sin perjuicio de los derechos que terceros hayan inscrito de conformidad al Código General de Aguas". Sobre este particular, DíAz (2020), p. 70, expresa la existencia de un deber de reconocimiento de los derechos de propiedad ancestral, que obedecerían a necesidades económicas, culturales y sociales de los pueblos de Chile, no bastando su configuración como mera expectativa. 
tierra y a las tradiciones de los pueblos originarios. A su respecto, no se verifica el sometimiento de estos usos a la lógica de la posesión inscrita, puesto que estos usos no están creados a partir de un caudal a extraer de la fuente natural de abastecimiento, sino en la mantención de dichos caudales in situ ${ }^{68}$. En otras palabras, la extensión de estos derechos obedece a parámetros geográficos y de protección ecosistémica. Estos usos prácticamente se oponen a la consideración de los usos privativos sobre las aguas y sus contornos responden con mayor precisión a lo que la doctrina denomina "derechos de la naturaleza" 69 .

En el respeto a la polifuncionalidad también debe considerarse la utilización de aguas provenientes de fuentes alternativas de abastecimiento. Nos referimos, por ejemplo, a las aguas provenientes de la desalación de aguas marinas, aunque ello quede sujeto a un régimen jurídico diverso porque, dada su abundancia, no resulta necesario constituir derechos de aprovechamiento en los mismos términos que ocurre respecto a las aguas terrestres. Sobre las aguas desaladas conviene señalar que se trata de la incorporación al régimen público terrestre de un recurso que proviene de una fuente no publificada (el agua del mar). Hoy, atendida la escasez de las aguas terrestres y la sobreexplotación de sus fuentes se hace necesario contar con una fuente alternativa de aguas para el suministro de la mayoría de las actividades económicas en que ellas constituyen un insumo, reservando las aguas terrestres (y dulces) para el abastecimiento de la población. Las aguas marinas son inagotables y para su aprovechamiento no existen mayores trabas en su acceso. En consecuencia, no se requiere la obtención de una concesión de aprovechamiento de aguas marinas. La concesión marítima no es un requisito para la extracción de las aguas del mar, sino que solo se requiere para ocupar un espacio, una "porción" del mar y establecer elementos flotantes en este. La liberalización en el aprovechamiento de las aguas marinas permite contrarrestar el costo que su utilización (costos energéticos y de desplazamiento) a que están sometidas y las convierte en el insumo perfecto para el desarrollo económico del país ${ }^{70}$.

${ }^{68}$ Paralelamente existen otros usos que tampoco están sujetos a la posesión inscrita, puesto que se refieren a ciertas circunstancias fácticas y de menor impacto. Esta categoría incluye las vertientes que nacen, corren y mueren dentro de una misma heredada y los lagos menores no navegables por buques de más de cien toneladas (art. 20 inciso segundo del $C A$ ) y los pozos cavados en suelo propio para la bebida y el consumo doméstico (art. 56 inciso $1 .^{\circ} \operatorname{del} C A$ ) y las aguas halladas en labores mineras (art. 56 inciso $2 .^{\circ} \mathrm{del} C A$ ), a las que nos referiremos infra.

${ }^{69}$ Un trabajo sobre el reconocimiento de los derechos de la naturaleza en materia de aguas puede encontrarse en CELume (2020).

${ }^{70}$ Sin perjuicio de que atendida su disponibilidad las aguas marinas no requieran de instrumentos específicos para su extracción, la clave ambiental representa un papel preponderante en lo que atañe a la disposición de las salmueras y de los subproductos originados con la desalinización, especialmente, cuando estos son arrojados de vuelta al mar. 
La necesidad de constitucionalizar el principio de la polifuncionalidad de las aguas y la protección de su función ambiental radica en las atribuciones de que podrá gozar la autoridad para evitar la afectación de aquellas fuentes naturales de abastecimiento que provean la conservación de los ecosistemas protegidos, fundada en la protección de los usos múltiples de las aguas. La DGA no solo estaría constreñida a otorgar DAA extractivos, sino que tendría que ponderar la reserva de fuentes de aguas con finalidades in situ. Este desafío impondría a la DGA una necesaria revisión del otorgamiento de DAA, utilizando parámetros más amplios que incorporen la variable ambiental en sus decisiones.

\section{La destinación específica del uso del agua y la priorización del uso para el consumo humano}

La priorización del uso de las aguas para el consumo humano supone la existencia y el reconocimiento de los diversos usos de las aguas y su destinación específica. La legislación actual no contiene normas sobre prelación de los usos de las aguas, porque tampoco el uso declarado es vinculante ${ }^{71}$.

El sometimiento del derecho de aprovechamiento a un uso específico no ha estado ausente de controversias. Durante los debates que tuvieron origen al interior de la Comisión de Estudios de Nueva Constitución, la Subcomisión de Propiedad propuso un texto del siguiente tenor:

“Todas las aguas son bienes nacionales de uso público; pero, en conformidad a la ley, podrán constituirse derechos de aprovechamiento sobre ellas para fines específicos $[\ldots]$ ".. ${ }^{\prime 2}$.

Este texto fue desechado por la Comisión de Estudios de la Nueva Constitución y no prosperó en la dictación de la actual $C P R$. Consecuencia de

${ }^{71} \mathrm{El} C A$ de 1951 contemplaba una prelación de usos del agua. A este respecto, el art. 30 de dicho texto legal señalaba: "Si se presentaren diversas solicitudes de merced para unas mismas aguas, su concesión se hará en el siguiente orden de preferencia:

1.o Bebida y servicio de agua potable de las poblaciones y centros industriales;

2.o Usos domésticos y saneamiento de poblaciones;

3.o Abastecimiento de ferrocarriles y elaboración de salitre;

4.o Regadío;

5.o Plantas generadoras de fuerza motriz o eléctrica;

6.o Industrias, molinos y fábricas, y

7.o Otros usos.

Dentro de cada clase serán preferidas las empresas de mayor importancia y utilidad, y en igualdad de condiciones preferirán según las fechas de sus solicitudes".

${ }^{72}$ Véase, en especial, las actas de la sesión n. ${ }^{\circ} 182^{\text {a }}$ de la Comisión Ortúzar, celebrada el 14 de enero de 1976. 
esta omisión, el legislador ha establecido la libertad de uso de las aguas del modo explicado supra. Sin embargo, esta libertad de uso ha determinado que la autoridad desconozca los actuales usos de las aguas.

La legislación ha intentado reparar esta omisión por medio de la incorporación de la memoria explicativa (introducida por la Ley n. ${ }^{\circ} 20017$, de 2005) y con la obligación de señalar en la solicitud de DAA el uso que se le dará a las aguas (introducida por la Ley n. ${ }^{\circ} 21064$, de 2018). Sin embargo, no existe una vinculación estricta al uso, ni los otorgamientos ni los cambios de uso de las aguas son autorizados por la autoridad administrativa en función de la sustentabilidad de la fuente de abastecimiento ${ }^{73}$.

La destinación a un uso específico implica una limitación al otorgamiento de los nuevos DAA puesto que la DGA deberá preferir unos por sobre otros, atendida la priorización que se disponga. En este sentido, las normas sobre remate (subasta de solicitudes) contenidas en el art. 142 del $C A$ solo podrían aplicarse para solicitudes que se refieran a un mismo uso. En cuanto al ejercicio del DAA, la destinación a un uso específico significaría que no se podría cambiar sin una previa autorización. Lo mismo ocurriría en la transferencia y en la transmisión de los DAA. A su vez, la DGA deberá llevar un registro público con los diferentes usos de las aguas y, a partir de la información que de él se extraiga, la Administración podrá elaborar políticas para fomentar y subsidiar determinados usos por sobre otros. Esta cuestión es relevante puesto que puede ir sentando las bases de una posible tarificación de los distintos usos de las aguas en la cual confluyan los intereses del Estado en proteger ciertos usos, como pueden ser los ecológicos o los de consumo humano, subvencionándolos frente a otros usos productivos que se podrían ver gravados de manera más o menos intensa de conformidad a los intereses generales, en la medida en que tal diferenciación no comporte una discriminación arbitraria.

Sin perjuicio de lo anterior, cabe señalar que el DAA no pierde su carácter de derecho patrimonial por su vinculación a un uso. Este podrá seguir siendo objeto de transferencias y transmisiones y no pierde su carácter de derecho real. Sin embargo, la destinación a un uso específico fragmenta los mercados conforme al uso vinculado a cada tipo.

${ }^{73}$ Sin perjuicio de ello, el inciso final del art. 147 bis dispone: “[...] procederá la constitución de derechos de aprovechamiento sobre aguas subterráneas, siempre que la explotación del respectivo acuífero sea la apropiada para su conservación y protección en el largo plazo, considerando los antecedentes técnicos de recarga y descarga, así como las condiciones de uso existentes y previsibles [...]". Esta norma permite a la administración "presumir" un determinado "factor de uso" de las aguas, sin contar con la información idónea sobre el uso real que se efectúa en una cuenca y sin poder controlar los cambios de uso que en ella se produzcan. 


\section{El derecho humano al agua}

El derecho humano al agua es producto de las interpretaciones que los organismos internacionales han hecho de textos de derecho internacional convencional, especialmente con fundamento en los arts. 11 y 12 del PIDESC $^{74}$. Así, como puntualiza Aniza García:

"De manera expresa el Comité [de DESC] ha reconocido que el acceso al agua es un derecho humano amparado por el artículo 11 del PIDESC, e indisolublemente asociado al derecho al más alto nivel posible de salud consagrado en el artículo 12, a los derechos a una alimentación y una vivienda adecuadas previstos en el mismo artículo 11 del Pacto. Por ello, el derecho humano al agua 'también debe considerarse conjuntamente con otros derechos consagrados en la Carta Internacional de Derechos Humanos, entre los que ocupa un lugar primordial el derecho a la vida y a la dignidad humana' (Obs. Gral. n. $\left.{ }^{\circ} 15,2002\right) " 75$.

En cuanto al contenido normativo de este derecho, Ángel Menéndez argumenta:

"El derecho al agua que aquí interesa es el que garantiza la disponibilidad del recurso para la satisfacción de las necesidades vitales y domésticas (alimento, higiene, salubridad), no para el riego, usos industriales u otras actividades, aunque puedan constituir el medio de vida de los usuarios"76.

Este derecho al agua se sintetiza en la posibilidad real que tiene el ordenamiento jurídico de proveer a todas las personas de un acceso igualitario y no discriminatorio a las fuentes naturales de abastecimiento con la finalidad de satisfacer las necesidades básicas del consumo doméstico, debiendo añadirse la creación de mecanismos que permitan su adecuada fiscalización. Como indica Sergio Salinas:

"Es evidente que el derecho al agua, como cualquier otro derecho, no es ilimitado. Factores como el carácter finito del recurso y los costes económicos ligados a su ejercicio conducen a desechar un derecho al agua entendido como reconociendo acceso inmediato y gratuito a ese bien a todos los usuarios con cualquier finalidad"77.

\footnotetext{
${ }^{74}$ En este sentido, Embid (2006), p. 20.

${ }^{75}$ García (2008), p. 186.

${ }^{76}$ Menéndez (2012), p. 197.

77 Salinas (2006), p. 106.
} 
Para algunos, como Iván Obando, el derecho humano al agua estaría reconocido indirectamente en el ordenamiento jurídico constitucional porque complementaría el ejercicio de otros derechos constitucionales, tales como: el derecho a la vida, el derecho a vivir en un ambiente libre de contaminación, el derecho a la protección de la salud, el derecho a la educación y el derecho a la protección del trabajo. Además, porque este derecho se incardinaría en ciertos principios constitucionales tales como: la igual dignidad de la persona humana, el principio de servicialidad del Estado, los principios de juridicidad, jerarquía normativa y de vinculación directa de las normas constitucionales, el deber estatal de velar por la no afectación del derecho a vivir en un medio ambiente libre de contaminación y de tutelar la preservación de la naturaleza. Así, este derecho formaría parte del bloque de constitucionalidad en virtud de la remisión que el art. $5^{\circ}$ inciso $2 .^{\circ}$ de la $C P R$, hace respecto de los derechos esenciales contenidos en los tratados internacionales ratificados por Chile y que se encuentran vigentes ${ }^{78}$.

En cualquier caso, la constitucionalización del derecho humano al agua permitirá reconocer el derecho fundamental de las personas a acceder a una dotación de agua potable suficiente y apta para satisfacer sus necesidades básicas de consumo, de uso personal y doméstico. Se trata, como lo ha señalado la Corte Suprema de que:

"[...] toda persona, por su dignidad de tal, tiene el derecho humano de acceso al agua potable, en condiciones de igualdad y no discriminación; derecho que posee, como correlato, el deber del Estado de garantizar el acceso en las mencionadas condiciones"79.

Con este reconocimiento, el DAA cede su carácter patrimonial para configurarse como un derecho público subjetivo que responde a ciertas necesidades de utilidad pública que escapan a los móviles que lo sujetan al derecho común. El DAA deja de configurarse como una titularidad que se somete a las reglas del tráfico jurídico privado para integrarse a un régimen exorbitante. En este régimen no son las leyes de la oferta y la demanda las que van a reasignar este derecho, sino que los requerimientos de salubridad de la comunidad.

La aplicación práctica del derecho humano al agua se traduce en la consagración legal de diversos mecanismos que aseguren que en el otorgamiento del DAA se efectuará una priorización para el consumo humano; que, en caso de redistribución de las aguas por causa de sequía, se reasig-

${ }^{78}$ Obando (2019), p. 117.

${ }^{79}$ X. G. con Anglo American Sur S.A (2021), considerando 9. ${ }^{\circ}$. 
narán de modo preferente para satisfacer las necesidades domésticas; y que, en caso de verse afectada la sustentabilidad de un acuífero y no haber aguas subterráneas suficientes para la bebida y el consumo doméstico, se procederá a reducir proporcionalmente el ejercicio de los demás DAA. Hoy, solo encontramos normas dispersas de priorización del consumo humano en la denegación parcial de solicitudes de derechos consuntivos cuando sea necesario reservar el recurso para el abastecimiento de la población (art. 147 bis inciso 3. ${ }^{\circ}$ del $C A$ ), en la facultad que tiene el dueño de un predio para cavar pozos en suelo propio para la bebida y el consumo doméstico (art. 56 inciso $1 .^{\circ} \mathrm{del} C A$ ), en la norma de expropiación de DAA (art. 27 del $C A$ ) y en el art. 68 de la Ley General de Pesca y Acuicultura ${ }^{80}$. Estas normas han sido insuficientes para poder cobijar una verdadera prioridad al consumo humano en nuestro ordenamiento vigente. Como reafirma Borja García:

"El Código de Aguas de Chile no hace alusión alguna a este derecho, sino exclusivamente al consumo humano (aunque sin establecer un orden de prelación prioritario a este fin). Así, el artículo 56, relativo a aguas subterráneas, el artículo 173 bis, referente a las sanciones frente a infracciones que afecten a la disponibilidad de las aguas destinadas a satisfacer el consumo humano; y finalmente, en el artículo 281 , relativo a las privaciones por parte del directorio, expresan que en ningún caso se podrá dejar sin el agua necesaria para la bebida, pero sin concretar cantidades de consumo ni necesidad" $"$.

Como se puede apreciar, la Administración deberá contar con herramientas de intervención suficientes y aptas para poder garantizar el ejercicio del derecho humano al agua. Así, el DAA se ve expuesto a ser modulado, restringido y limitado en aras de la protección de un derecho humano. Como refiere Sara Larraín:

"La experiencia chilena, es una clara muestra de la importancia de que los países resguarden el derecho al agua como un recurso básico para la vida, y eviten las políticas que conducen a su mercantilización y privatización. Incluir las concepciones y derechos de los pueblos originarios y la participación de la sociedad civil en su

${ }^{80}$ Esta norma dispone que la DGA deberá preferir a la persona que acredite la calidad de acuicultor, en el caso de oposición a que se refiere el inciso $3 .^{\circ} \mathrm{del}$ art. $141 \mathrm{del} C A$, salvo aquellas referidas a la obtención de derechos consuntivos de aguas destinadas a consumo humano.

${ }^{81}$ García (2020), p. 175. 
conjunto son fundamentales para la re-orientación de las políticas de agua en nuestra región, re-definiendo este recurso como un derecho humano básico y un bien colectivo, fundamental para la vida de las personas y del planeta; y por lo tanto, inalienable y no mercantilizable" ${ }^{\prime 2}$.

Sin perjuicio de lo anterior, cabe mencionar que con fecha $17 \mathrm{de} \mathrm{ju}$ nio de 2021, se publicó en el Diario Oficial la Ley n. ${ }^{\circ}$ 21348, que faculta al Presidente de la República asegurar el uso prioritario del agua para el consumo humano, el saneamiento y el uso doméstico de subsistencia, durante la vigencia de un estado de excepción constitucional de catástrofe por calamidad pública. En su historia legislativa, la idea matriz o fundamental del proyecto de ley consistía en garantizar, en situaciones de pandemia, crisis sanitaria y desastres naturales, el acceso y disponibilidad, en cantidades suficientes, de agua a la población afectada orientando legalmente las atribuciones del Presidente de la República. Por un lado, la legislación vigente no ha definido el consumo humano ni el uso doméstico de subsistencia. Sin embargo, el art. 51 del decreto supremo n. ${ }^{\circ} 203$, de 2013 del Ministerio de Obras Públicas, establece la definición de "bebida y uso doméstico" y lo refiere al uso de una persona y su familia, para la bebida, el aseo personal y el cultivo de productos indispensables para su subsistencia, sin fines económicos o comerciales. La jurisprudencia, por su parte, ha resuelto en este mismo sentido, señalando:

"El vocablo 'doméstico' [...], debe entenderse que es, 'lo perteneciente o relativo a la casa u hogar'. El concepto de 'doméstico' desplaza la utilización para fines económicos o comerciales, como lo constituye la extracción de agua a través de un pozo que se utiliza en beneficio de las plantaciones [...]"83.

De este modo, el sentido y alcance de esta nueva disposición legal lo podemos circunscribir a un consumo mínimo y necesario para la supervivencia de una persona y su familia.

Por otro lado, las facultades otorgadas por esta nueva ley no se refieren al $C A$. Sin perjuicio de ello, creemos que estas necesariamente deben reconducirse a la legislación vigente y traducirse en limitaciones o restricciones a los DAA, las que operarán mientras esté vigente el estado de excepción constitucional. Así, en virtud de esta ley, la Administración podrá intervenir redistribuyendo los derechos en una cuenca, sin nece-

${ }^{82}$ LARRAÍn (2006).

${ }^{83}$ J. A. con Dirección General de Aguas (2016), considerando 7.. 
sidad de que exista un decreto de escasez y sin tener que indemnizar, en caso que, producto de la redistribución, un titular de derechos reciba menor proporción de aguas que la que le correspondería de conformidad a las disponibilidades existentes. Asimismo, el Presidente de la República podrá autorizar que se extraigan aguas con la finalidad de satisfacer el consumo doméstico de subsistencia, sin necesidad de que se tramite una concesión administrativa previa. A su vez, estas facultades permitirán a la Administración reducir el ejercicio de los DAA en un acuífero, ya no a prorrata, sino priorizando aquellos derechos que estén destinados al consumo humano. Por último, estas facultades permitirán a la DGA reservar aguas para el consumo de la población sin necesidad de que exista una solicitud pendiente susceptible de ser denegada parcialmente.

\section{Conclusiones}

La propietarización constitucional de las aguas contenida en el inciso final del art 19 núm. 24 de la $C P R$ solo ha contribuido a reforzar el carácter patrimonial privado de los DAA. Dicho carácter se traduce en la subsunción de las características del derecho de propiedad a su respecto. En este sentido, los DAA tienden a ser absolutos, exclusivos y perpetuos. La $C P R$ ha establecido una reserva legal en virtud de la cual la ley ha determinado la forma de obtener tales derechos, sus características esenciales, sus facultades y sus limitaciones en atención a la función social de la propiedad. Asimismo, ellos han quedado protegidos con la acción de protección constitucional.

Dentro de los márgenes que configuran el derecho de propiedad, el legislador ha configurado los derechos de aprovechamiento bajo la lógica de la libre transferibilidad y la libertad de su uso, otorgándoles carácter indefinido y sin determinar a su respecto causales de caducidad o extinción. La protección del núcleo esencial del DAA, configurado al modo de un derecho de propiedad, se ha traducido en que ellos estén sujetos a escasas limitaciones en su constitución y en su ejercicio.

La consideración patrimonial privada del DAA plantea serios cuestionamientos. Este se crea ex novo a partir de un procedimiento concesional y está invariablemente sujeto al interés público que justifica su otorgamiento. Por su parte, la ausencia de un marco constitucional que arroje ciertas directrices al legislador sobre la regulación legal de las aguas ha perpetrado el afianzamiento de aquellas características que lo asemejan aún más a los parámetros inflexibles del derecho de propiedad. Un marco rígido, como el de la propiedad, impide al legislador adecuar el DAA a la satisfacción de la multiplicidad de usos que demandan las aguas. 
Con independencia de la consagración constitucional de las aguas como un bien nacional de uso público, proponemos que la $C P R$ elabore un marco conceptual que contenga al menos los principios de interés público en la asignación del recurso, la protección de la polifuncionalidad de las aguas y de su función ambiental, la destinación específica del uso del agua, la priorización del uso para el consumo humano y el derecho al agua. Estas consideraciones afectan la configuración jurídica del DAA tal y como los conocemos en la actualidad, y lo exponen a alejarse de la lógica civil patrimonial que hasta ahora lo ha impregnado. El DAA se encontraría subsumido en categorías administrativas que lo condicionarían al interés público que lo justifica. Dicho interés público ya no se encontraría preferentemente radicado en la asignación de los DAA a sus usos de mayor valor, sino a un equilibrio entre los diversos usos (tanto extractivos como no extractivos) y a la protección de la certeza jurídica.

\section{Bibliografía CitADA}

Arévalo, Gonzalo (2011a). "De los modos derivativos de adquirir el dominio y de la prescripción del derecho de aprovechamiento de aguas", en Alejandro Vergara (dir.). Código de Aguas comentado. Santiago: Abeledo Perrot.

ARÉvalo, Gonzalo (2011b). "Derechos de aprovechamiento de aguas subterráneas que se adquirieron por el solo ministerio de la ley", en Alejandro Vergara (dir.). Código de Aguas comentado. Santiago: Abeledo Perrot.

ArÉvalo, Gonzalo (2011c). "El derecho de aprovechamiento de aguas, sus características y los principios que lo informan", en Alejandro Vergara (dir.). Código de Aguas comentado. Santiago: Abeledo Perrot.

Atria, Fernando y Constanza Salgado (2015). La propiedad, el dominio público y el régimen de aprovechamiento de aguas en Chile. Santiago: Thomson Reuters.

Bauer, Carl J. (2002). Contra la corriente. Santiago: LOM Ediciones.

Boettiger, Camila (2013). "Caudal ecológico o mínimo: regulación, críticas y desafíos”, en Actas de Derecho de Aguas, n. ${ }^{\circ}$ 3. Santiago.

Celume, Tatiana (2013). Régimen público de las aguas. Santiago: Thomson ReutersLegal Publishing.

Celume, Tatiana (2020). "Origen y fuente constitucional de los derechos de la naturaleza en Chile. Una perspectiva desde la lógica ambiental del agua”, en María del Pilar GARCía PACHÓN (dir.). Reconocimiento de la naturaleza y de sus componentes como sujetos de derechos. Bogotá: Ediciones Universidad Externado de Colombia.

Comisión de Agricultura del Senado (2020). "Informe recaído en el Boletín 7543-12 sobre Reforma al Código de Aguas". Disponible en http://senado. $\mathrm{cl} /$ appsenado/index.php? $\mathrm{mo}=$ tramitacion $\& \mathrm{ac}=$ getDocto\&iddocto $=4653 \& \mathrm{ti}$ podoc=docto_comision [fecha de consulta: 24 de mayo de 2021]. 
DGA (2009). "Reserva del río Cochamó para la conservación ambiental y el desarrollo local de la cuenca". Disponible en https://snia.mop.gob.cl/sad/ REH5152.pdf [fecha de consulta: 24 de mayo de 2021].

DGA (2012). "Informe técnico sobre análisis preliminar de planes de alerta temprana con condicionamiento de derechos". Disponible en https://snia.mop. gob.cl/sad/ADM5392.pdf [fecha de consulta: 24 de mayo de 2021].

DGA (2015). "Análisis de caudales de reserva de agua superficial para el desarrollo de la cuenca del río Pascua, Región de Aysén del General Carlos Ibáñez del Campo". Disponible en https://snia.mop.gob.cl/sad/ADM5269v1.pdf [fecha de consulta: 24 de mayo de 2021].

DíAz, Karenn (2020). "Crisis del agua en el norte de Chile. Derecho y cultura en los Andes. Sobre los efectos irracionales del derecho”. Diálogo Andino, n. ${ }^{\circ} 61$. Arica.

Embid, Antonio (2006). "El derecho al agua en el marco de la evolución del derecho de aguas", en Antonio Embid (dir.) El derecho al agua. Navarra: Aranzadi.

GarcíA, Aniza (2008). El derecho humano al agua. Madrid: Editorial Trotta.

GARCÍA, Borja (2020). "La compatibilidad del derecho humano al agua con la legislación chilena: el reconocimiento latinoamericano de este Derecho". Ius et Praxis, año 26, n. ${ }^{\circ}$ 3. Talca.

Guzmán, Alberto y Ernesto Ravera (1998). Estudio de las aguas. Santiago: Ediciones Jurídicas Congreso.

LARraín, Camilo (2016). "Análisis jurisprudencial de los aspectos medioambientales del Derecho de Aguas", en Jorge Bertrand (ed.). Derecho ambiental y recursos naturales Consolidación de doctrinas y nuevos desafíos. Santiago: Universidad de Los Andes.

LARRAÍn, Sara (2006). "El agua en Chile: entre los derechos humanos y las reglas del mercado". Polis, Revista de la Universidad Bolivariana, vol. 5, núm. 14. Santiago.

LiRA, Pedro y Lorenzo de la Maza (1940). Régimen legal de las aguas en Chile. Santiago: Editorial Nascimento.

MEnÉndez, Ángel (2012). "El agua como bien jurídico global: el derecho humano al agua". Anuario de la Facultad de Derecho de la Universidad Autónoma de Madrid. Disponible en https://repositorio.uam.es/handle/10486/662703 [fecha de consulta: 24 de mayo de 2021].

MEzA, Catalina (2014). "Aplicación de la patente por no uso de las aguas en Chile”. Actas de Derecho de Aguas, n. ${ }^{\circ}$ 4. Santiago.

OвANDo, Iván (2019). "El derecho humano al agua revisitado: antecedentes normativos e implicancias jurídicas". Revista de Derecho Administrativo Económico, n. ${ }^{\circ}$ 27. Santiago.

Quezada, Flavio (2018). "Bases constitucionales de la expropiación”, en Miriam Henríquez y Enrique Rajevic (coords.). Derecho de propiedad: enfoques de derecho público. Santiago: DER Ediciones. 
RECABARREN, Óscar (2016). "El estándar del derecho de aguas desde la perspectiva del derecho internacional de los derechos humanos y del medio ambiente". Estudios Constitucionales, año 14, n. ${ }^{\circ} 2$. Talca.

REYES, Jorge (1960). Naturaleza jurídica del permiso y de la concesión sobre bienes nacionales de uso público. Santiago: Editorial Jurídica de Chile.

Rivera, Daniela (2013). Usos y derechos consuetudinarios de aguas. Su reconocimiento, subsistencia y ajuste. Santiago: Thomson Reuters.

Rivera, Daniela (2015). "Diagnóstico jurídico de las aguas subterráneas". Ius Et praxis, vol. 21, n. ${ }^{\circ}$ 2. Disponible en http://derechoygestionaguas.uc.cl/images/ PDF/Diagnstico-Jurdico-de-las-Aguas-Subterrneas---Daniela-Rivera-bravo. pdf [fecha de consulta: 24 de mayo de 2021].

Rivera, Daniela (2018). "Alumbrando conflictos: disponibilidad y asignación de derechos de aguas subterráneas en la jurisprudencia chilena”. Revista de Derecho (Valdivia), vol. xxxI, n. ${ }^{\circ}$ 1. Disponible en http://revistas.uach.cl/index.php/ revider/article/view/3125 [fecha de consulta: 24 de mayo de 2021].

Rivera, Daniela y Alejandro Vergara (2015). Informe académico para el proyecto Colecciones Jurídicas de la Corte Suprema. Disponible en http://derechoygestionaguas.uc.cl/images/PDF/Hallazgo-de-aguas-en-labores-mineras. pdf

Rossel, Sergio (1960). "Del dominio y aprovechamiento de las aguas", en Ana HeDERRA (dir.). Comentarios al Código de Aguas. Santiago: Editorial Jurídica de Chile.

Salinas, Sergio (2006). "El derecho al agua como Derecho humano. Contenido normativo y obligaciones de los Estados", en Antonio EmBiD (dir.). El derecho al agua. Navarra: Editorial Thomson Aranzadi.

SANTELICES, Humberto (2009). Tres temas de derecho registral. Santiago: Editorial Metropolitana.

SiLva, María Pía (2018). "El estatuto del derecho de propiedad en la Constitución de 1980", en Miriam HenríQuez y Enrique Rajevic (coords.) Derecho de propiedad: enfoques de derecho público. Santiago: DER Ediciones.

Vergara, Alejandro (1998). Derecho de aguas. Santiago: Editorial Jurídica de Chile.

Vergara, Alejandro (2011). "Propiedad y suma divisio de derechos de aprovechamiento de aguas", en Alejandro Vergara (dir.). Código de Aguas comentado. Santiago: Abeledo Perrot.

Vergara, Alejandro (2017). Derecho de aguas: identidad y transformaciones. Santiago: Ediciones Universidad Católica.

Zuluaga, Ricardo (2017). "Los principios en el derecho ambiental". Revista de Derecho (Universidad Católica Dámaso A. Larrañaga, Facultad de Derecho), n. ${ }^{\circ} 16$. Disponible en www.scielo.edu.uy/pdf/rd/n16/2393-6193-rd-16-00101.pdf [fecha de consulta: 26 de junio de 2021]. 


\section{Normas citadas}

Constitución Política del Estado Plurinacional de Bolivia.

Constitución Política de la República de Chile.

Constitución de la República del Ecuador.

Constitución Política de los Estados Unidos Mexicanos.

Código de Aguas de Chile.

Código Civil de Chile.

Código de Minería de Chile.

Decreto ley n. ${ }^{\circ}$ 2603, modifica y complementa acta constitucional n. ${ }^{\circ} 3$; y establece normas sobre derechos de aprovechamiento de aguas y facultades para el establecimiento del régimen general de aguas. Diario Oficial de la República de Chile, Santiago, 27 de abril de 1979.

Decreto Supremo del MOP n. ${ }^{\circ}$ 203/14, aprueba reglamento sobre normas de exploración y explotación de aguas subterráneas. Diario Oficial de la República de Chile, Santiago, 7 de marzo de 2014.

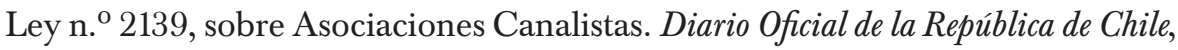
Santiago, 20 de noviembre de 1908.

Ley n. ${ }^{\circ} 19253$, establece normas sobre protección, fomento y desarrollo de los indígenas, y crea la Corporación Nacional de Desarrollo Indígena. Diario Oficial de la República de Chile, Santiago, 5 de octubre de 1993.

Ley n. ${ }^{\circ} 20017$, modifica el Código de Aguas. Diario Oficial de la República de Chile, Santiago, 16 de junio de 2005.

Ley n. ${ }^{\circ} 21064$, introduce modificaciones al marco normativo que rige las aguas en materia de fiscalización y sanciones. Diario Oficial de la República de Chile, Santiago, 27 de enero de 2018.

\section{Jurisprudencia citada}

Grupo Cámara de Diputados de Chile (1997): Tribunal Constitucional, 16 de septiembre de 1997, rol n. ${ }^{\circ}$ 260-97, sobre Requerimiento para resolver cuestiones de constitucionalidad.

H. L. y otros (2006): Tribunal Constitucional, 20 de junio de 2006, rol n. ${ }^{\circ}$ 513-06, sobre Requerimiento de inaplicabilidad por inconstitucionalidad.

W. G. (2008): Tribunal Constitucional, 5 de diciembre de 2008, rol n. ${ }^{\circ} 1281$ 09, sobre requerimiento de inaplicabilidad por inconstitucionalidad.

S. Q. L. (2009): Tribunal Constitucional, 19 de enero de 2009, rol n. ${ }^{\circ}$ 1309-09, sobre Requerimiento de inaplicabilidad.

HidroAysén S.A con MOP (2017): Corte de Apelaciones, 15 de mayo de 2017, rol n. ${ }^{\circ} 2396-15$ y rol n. ${ }^{\circ} 2395-15$, sobre requerimiento de reclamación.

J. C. (2014): Tribunal Constitucional, 18 de diciembre de 2014, rol n. ${ }^{\circ} 2759-14$, sobre requerimiento de inaplicabilidad por inconstitucionalidad. 
Agrícola San Juan de Huinca Ltda. (2016): Tribunal Constitucional, 27 de enero de 2016, rol n. ${ }^{\circ} 3146-16$, sobre requerimiento de inaplicabilidad por inconstitucionalidad.

J. A. con Dirección General de Aguas (2016): Corte de Apelaciones, 22 de diciembre de 2016, rol 1250-2016, sobre recurso de reclamación.

Sucesión P. H. con Dirección General de Aguas Cuarta Región (2013): Corte Suprema, 27 de marzo de 2013, rol 7.381-2011, sobre recurso de casación.

Sur Electricidad y Energía S.A (2017): Corte de Apelaciones, 17 de octubre de 2017, rol n. ${ }^{\circ} 352-10$, sobre recurso de reclamación.

X. G. con Anglo American Sur S.A (2021): Corte Suprema, 18 de enero de 2021, rol n. ${ }^{\circ}$ 72.198-2020, sobre recurso de protección.

SigLAS Y ABREVIATURAS

art. artículo

arts. artículos

CA Código de Aguas

CE Constitución española

coord. coordinador

coords. coordinadores

CPR Constitución Política de la República

DAA derecho de aprovechamiento de aguas a veces derechos de aprovechamiento de aguas

DESC Derechos Económicos, Sociales y Culturales

DGA Dirección General de Aguas

dir. director

ed. editor

Fondecyt Fondo Nacional de Desarrollo Científico y Tecnológico

http Hypertext Transfer Protocol

https Hypertext Transfer Protocol Secure

Ltda. Limitada

MOP Ministerio de Obras Públicas

n. ${ }^{\circ}$ a veces núm. número

Obs. Gral. Observación general

op. cit. opere citato (obra citada)

p. página

PIDESC Pacto Internacional de Derechos Económicos, Sociales y Culturales 


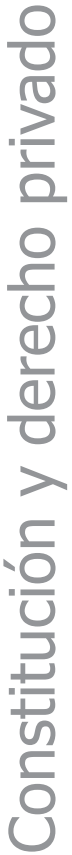

\author{
pp. páginas \\ S.A. sociedad anónima \\ STC Sentencia del Tribunal Constitucio- \\ nal \\ TC Tribunal Constitucional \\ vol. volumen \\ www World Wide Web
}

